\title{
The genome of the intracellular bacterium of the coastal bivalve, Solemya velum: a blueprint for thriving in and out of symbiosis
}

\author{
Oleg Dmytrenko ${ }^{1}$, Shelbi L Russell', Wesley T Loo ${ }^{1}$, Kristina M Fontanez ${ }^{2}$, Li Liao ${ }^{3}$, Guus Roeselers ${ }^{4}$, Raghav Sharma ${ }^{5}$, \\ Frank J Stewart ${ }^{5}$, Irene LG Newton ${ }^{6}$, Tanja Woyke ${ }^{7}$, Dongying Wu ${ }^{8}$, Jenna Morgan Lang ${ }^{8}$, Jonathan A Eisen ${ }^{8}$ \\ and Colleen M Cavanaugh ${ }^{1^{*}}$
}

\begin{abstract}
Background: Symbioses between chemoautotrophic bacteria and marine invertebrates are rare examples of living systems that are virtually independent of photosynthetic primary production. These associations have evolved multiple times in marine habitats, such as deep-sea hydrothermal vents and reducing sediments, characterized by steep gradients of oxygen and reduced chemicals. Due to difficulties associated with maintaining these symbioses in the laboratory and culturing the symbiotic bacteria, studies of chemosynthetic symbioses rely heavily on culture independent methods. The symbiosis between the coastal bivalve, Solemya velum, and its intracellular symbiont is a model for chemosynthetic symbioses given its accessibility in intertidal environments and the ability to maintain it under laboratory conditions. To better understand this symbiosis, the genome of the $S$. velum endosymbiont was sequenced.
\end{abstract}

Results: Relative to the genomes of obligate symbiotic bacteria, which commonly undergo erosion and reduction, the $S$. velum symbiont genome was large (2.7 Mb), GC-rich (51\%), and contained a large number (78) of mobile genetic elements. Comparative genomics identified sets of genes specific to the chemosynthetic lifestyle and necessary to sustain the symbiosis. In addition, a number of inferred metabolic pathways and cellular processes, including heterotrophy, branched electron transport, and motility, suggested that besides the ability to function as an endosymbiont, the bacterium may have the capacity to live outside the host.

Conclusions: The physiological dexterity indicated by the genome substantially improves our understanding of the genetic and metabolic capabilities of the $S$. velum symbiont and the breadth of niches the partners may inhabit during their lifecycle.

Keywords: Symbiosis, Chemosynthesis, Sulfur oxidation, Respiratory flexibility, $\mathrm{H}^{+} / \mathrm{Na}^{+}$-membrane cycles, Calvin cycle, Pyrophosphate-dependent phosphofructokinase, Heterotrophy, Motility, Mobile genetic elements

\section{Background}

Symbiosis is one of the major driving forces of evolutionary adaptation. Chloroplasts and mitochondria are examples of ancient symbiotic partnerships which played key roles in the emergence and diversification of eukaryotic life on Earth [1]. Bacteria have been found in symbioses with

\footnotetext{
* Correspondence: jaeisen@ucdavis.edu; cavanaug@fas.harvard.edu

${ }^{8}$ UC Davis Genome Center, 451 East Health Sciences Drive, Davis, CA

95616-8816, USA

'Department of Organismic and Evolutionary Biology, Harvard University, 16 Divinity Avenue, 4081 Biological Laboratories, Cambridge, MA 02138, USA

Full list of author information is available at the end of the article
}

organisms as diverse as plants, insects, marine invertebrates, and protists [2-5], expanding metabolic capabilities of the partners and allowing them to occupy otherwise unavailable ecological niches. Despite the ubiquity of such mutualistic associations and their importance to health and the environment, studies of many host-associated microorganisms have been complicated by difficulties in both the maintenance of symbiotic organisms in culture and the inability to genetically manipulate them. However, progress in culture-independent techniques has allowed

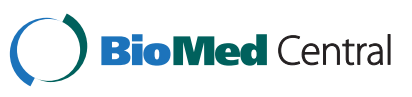

(c) 2014 Dmytrenko et al.; licensee BioMed Central Ltd. This is an Open Access article distributed under the terms of the Creative Commons Attribution License (http://creativecommons.org/licenses/by/4.0), which permits unrestricted use, distribution, and reproduction in any medium, provided the original work is properly credited. The Creative Commons Public Domain Dedication waiver (http://creativecommons.org/publicdomain/zero/1.0/) applies to the data made available in this article, unless otherwise stated. 
for rapid advances in understanding symbiosis diversity, evolution, genetics, and physiology [6-8]

Symbioses between chemoautotrophic bacteria and invertebrates are ubiquitous in reducing marine habitats, such as deep-sea hydrothermal vents and coastal sediments. In these environments, the symbiotic bacteria derive energy by oxidizing reduced inorganic molecules (e.g., sulfide) and fix carbon dioxide for biomass production. Their hosts have evolved behavioral, physiological, and biochemical adaptations for capturing and delivering the required electron donors and acceptors to the symbionts. In return, these invertebrates obtain their nutrition from bacterial chemosynthesis $[5,9]$.

Solemya velum and its endosymbionts is one of the bestdescribed chemoautotrophic symbioses. The host, a protobranch bivalve, lives in coastal nutrient-rich sediments where it builds Y-shaped burrows that span the oxicanoxic interface, allowing access to both reduced inorganic sulfur as an energy source and oxygen for use as a terminal oxidant [10]. The symbionts, which constitute a single $16 \mathrm{~S}$ rRNA phylotype of $\gamma$-proteobacteria [11], are localized to specialized epithelial cells (bacteriocytes) in the gills, separated from the cytoplasm by a peribacterial membrane. Using energy from the oxidation of sulfide, the symbionts fix $\mathrm{CO}_{2}$ via the Calvin-Benson-Bassham Cycle [12,13]. Primary production in the symbionts sustains the host, which has only a rudimentary gut and cannot effectively filter-feed [14,15]. Many key properties of this symbiosis still remain to be characterized, including the exchange of metabolites and signals between the symbiont and the host and the mechanism of symbiont acquisition at each new host generation (i.e., symbiont transmission mode).

The mode by which $S$. velum acquires its symbionts has important implications for understanding symbiont genome evolution. Symbiont-specific genes have been amplified from the host ovarian tissue of both $S$. velum and its congener, $S$. reidi $[16,17]$, raising the hypothesis that symbionts are transmitted maternally (vertically) between successive host generations via the egg. Vertical transmission has also been inferred in deep-sea clams of the Vesicomyidae $[18,19]$, in which symbionts have a reduced genome size $(1.2 \mathrm{Mb})$ and appear to be obligately associated with their host [20-23]. In vesicomyid symbioses, host and symbiont phylogenies are largely congruent, a pattern consistent with vertical symbiont transmission [24]. Nonetheless, instances of lateral symbiont movement among some vesicomyids have been inferred based on decoupling of symbiont and host evolutionary trajectories [25], bringing diverse symbiont strains into contact and creating opportunities for symbiont genome evolution via recombination $[26,27]$. In the Solemyidae, on the other hand, symbionts of different Solemya species are scattered across phylogenetic clades (i.e., polyphyly), indicating distinct evolutionary origins relative to the monophyly of the hosts $[5,28]$. A preliminary analysis was unable to definitively resolve the extent of genetic coupling between the $S$. velum host and its symbionts in populations along the southern New England coast [26]. These patterns may be the result of a physical decoupling of symbiont and host lineages, possibly due to lateral symbiont transmission between hosts.

It is therefore possible that transmission in solemyid symbioses, as in vesicomyids, involves a combination of both vertical passage through the maternal germ line and lateral acquisition of symbionts from the environment or other co-occurring host individuals. Such a mixed transmission mode could strongly impact symbiont genome evolution by creating opportunities for lateral gene transfer, relieving the constraints of genetic bottlenecks imposed by strict vertical transmission $[29,30]$, and imposing selective pressures for the maintenance of diverse functions in the symbiont genome that would mediate survival outside the host. The genome of the $S$. velum symbiont will provide insights into the transmission mode of this symbiont, define a framework for examining its physiological adaptations, and supply a reference sequence for future studies of the ecology and evolution of solemyid symbionts.

Here we present an analysis of the genome from the $S$. velum symbiont. First, genes that encode core metabolic functions are discussed. Emphasis is placed on bioenergetics, autotrophy, heterotrophy, and nitrogen metabolism, which indicate metabolic potential beyond strict chemolithoautotrophy. Genes encoding cellular functions that pertain to the symbiotic lifestyle are also analyzed. A special focus is on the processes, such as membrane transport, sensing, and motility that may be involved in interactions of the symbiont with the host and the environment. Wherever appropriate, the gene content is compared to that of free-living and host-associated bacteria, in particular the intracellular chemosynthetic symbionts of the vesicomyid clams, Calyptogena magnifica [22] and Calyptogena okutanii [20], the vestimentiferan tubeworms, Riftia pachyptila [31] and Tevnia jerichona [32], the scaly-foot snail, Crysomollon squamiferum, [33] and the marine oligochaete worm, Olavius algarvensis, [34]. This comprehensive analysis defines the $S$. velum symbiont as a metabolically versatile bacterium adapted to living inside the host but also potentially capable of survival on the outside. It informs attempts to culture the symbionts and generates multiple intriguing hypotheses that now await experimental validation.

\section{Results and discussion}

\section{General genome features}

The genome of the S. velum symbiont consists of 10 non-overlapping scaffolds, totaling 2,702,453 bp, with an average $\mathrm{G}+\mathrm{C}$ content of $51 \%$. The three largest scaffolds (1.21 Mb, $0.89 \mathrm{Mb}, 0.54 \mathrm{Mb}$ ) contain $97.8 \%$ of the total 
genomic sequence and $98.4 \%$ of the predicted genes (Additional file 1: Table S1). Assembly of the scaffolds into a closed genome was prevented by stretches of single nucleotides or groups of a few nucleotides repeated up to 70 times that could not be spanned. However, the high depth of sequence coverage and the presence of all 31 core bacterial phylogenetic gene markers [35] suggest that most gene-coding regions were detected in the analysis. Nevertheless, as the genome is not closed, a definitive list of all symbiont genes could not be made.

An overview of the $S$. velum symbiont genome compared to selected symbiotic and free-living $\gamma$-proteobacteria, including other thiotrophs, is presented in Table 1. Briefly, $90.7 \%$ of the genome sequence encodes 2,757 genes, on average 885 bp long. 2,716 (98.5\%) genes are proteincoding. Function was predicted for $1,988(72.1 \%)$ of all the genes, while 769 (27.9\%) were identified as encoding hypothetical proteins. 382 genes $(13.8 \%)$ have one or more paralog in the genome, with the largest paralogous group encoding transposases associated with mobile elements. The genome contains a single ribosomal RNA (rRNA) operon and 38 transfer RNAs (tRNA) corresponding to the 20 standard proteinogenic amino acids. Due to the wobble base-pairing [36], tRNAs for each given amino acid can pair with any codon in the genome for that amino acid (Additional file 2: Table S2).

A model of the symbiont cell based on functional predictions is presented in Figure 1 (see Additional file 3: Table S3 for the list of the corresponding gene products). When grouped into COG categories [37], the largest number of genes within the genome of the S. velum symbiont was associated with metabolism of coenzymes, transcription, posttranscriptional modification of proteins, cell division, DNA replication, and energy metabolism (Figure 2). Based on a BLASTN [38] search against the NCBI-nr database analyzed by MEGAN [39], 1,735 of the genes in the genome were assigned to $\gamma$-proteobacteria, mainly other sulfur-oxidizing symbionts (197 genes) and bacteria from the order of Chromatiales (184 genes). Among the genes within $\gamma$-proteobacteria, 897 could not be assigned to a lower-level taxon in the NCBI taxonomy. 37 genes had the closest matches to eukaryotes and 6 to archaea. No taxa could be assigned to 29 genes, while 212 genes had no hits in the NCBI-nr database (Figure 3). The majority of the sequences designated as "eukaryotic" were hypothetical and produced low percent amino acid identity matches in the BLASTN search.

\section{Metabolic functions Chemolithotrophy}

The S. velum symbiont, and chemoautotrophic symbionts in general, are remarkable in their ability to support almost all the metabolic needs of their metazoan hosts with energy derived from thiotrophy. Present genome data illustrate the ability of the $S$. velum symbiont to oxidize both hydrogen sulfide and thiosulfate via diverse pathways, in agreement with previous measurements of symbiont gene expression [40] and in vitro experiments showing that both substrates can stimulate carbon fixation in the symbiont $[10,13]$. The S. velum symbiont genes involved in the oxidation of reduced sulfur species are most closely related to those of the purple sulfur $\gamma$-proteobacterium, Allochromatium vinosum (Figure 4), in which the genetic components and the biochemical mechanisms of sulfur metabolism have been well characterized [41].

Periplasmic sulfide and thiosulfate oxidation In the periplasm of the S. velum symbiont, sulfide, thiosulfate, and, possibly, elemental sulfur, may be oxidized for energy by the Sox system, which is represented in the genome (Figure 4). The encoded SoxYZAXB, flavocytochrome $c$ dehydrogenase (FccAB), and type I and IV sulfide-quinone reductases (Sqr) potentially reduce cytochromes $c$ and quinones, which along the course of the electron-transport chain translate into membrane-ion gradients, $\mathrm{NADH}$, and ATP, ultimately fueling biosynthetic and other energyrequiring cellular processes, including autotrophy (Figure 1). In $A$. vinosum and the green non-sulfur bacterium, Chlorobium tepidum, SoxYZ, SoxAX, and SoxB proteins participate in the formation of transient sulfur deposits as intermediates during sulfur oxidation [43]. In fact, sulfur deposits are common to all known sulfur-oxidizing bacteria (SOB) which, like the S. velum symbiont, lack SoxCD sulfur dehydrogenase (Figure 4) [44], including the symbionts of the hydrothermal vent tubeworm, $R$. pachyptila [31,45], and the clam, C. magnifica [22,46]. Microscopicallydetectable intracellular or extracellular sulfur has not been observed either in the symbiont-containing gills of S. velum or directly within the symbionts (Cavanaugh, unpublished observation). Absence of sulfur deposits may be attributed to a very rapid consumption of any available reduced sulfur substrate. This agrees with the fact that the $S$. velum symbiont have the highest known carbon fixation rate, and, hence, demand for energy, of all the studied

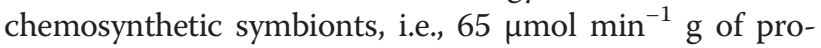
tein $^{-1}$ [13] compared to $0.45 \mu \mathrm{mol} \mathrm{m^{-1 }}$ g of protein ${ }^{-1}$ of the next highest rate measured in the symbionts of $R$. pachyptila [47]. Alternatively, in the $S$. velum symbiont intermediate sulfur may be stored in a chemical form that is not easily observed microscopically.

Cytoplasmic sulfide oxidation Energy generating oxidation of sulfide to sulfite may be catalyzed in the cytoplasm of the $S$. velum symbiont by the reverse-acting dissimilatory sulfite reductase (rDsr) pathway (Figure 1). All of the enzymes and accessory proteins required for this pathway are encoded in a dsrABEFHCMKLJOPNRS 
Table 1 General genome features of the S. velum symbiont in comparison to other $\gamma$-proteobacteria

\begin{tabular}{|c|c|c|c|c|c|c|c|c|c|}
\hline & $\begin{array}{l}\text { Solemya velum } \\
\text { endosymbiont }\end{array}$ & $\begin{array}{l}\text { Riftia pachyptila } \\
\text { endosymbiont* }\end{array}$ & $\begin{array}{c}\text { Calyptogena } \\
\text { magnifica } \\
\text { endosymbiont }\end{array}$ & $\begin{array}{c}\text { Calyptogena } \\
\text { okutanii } \\
\text { endosymbiont }\end{array}$ & $\begin{array}{c}\text { Buchnera } \\
\text { aphidicola } \\
\text { APS }\end{array}$ & $\begin{array}{l}\text { Ca. Carsonella } \\
\text { ruddii PV }\end{array}$ & $\begin{array}{l}\text { Thiomicrospira } \\
\text { crunogena } \\
\text { XCL-2 }\end{array}$ & $\begin{array}{l}\text { Allochromatium } \\
\text { vinosum } \\
\text { DSM } 180\end{array}$ & $\begin{array}{c}\text { Escherichia coli } \\
\text { K12 DH1, } \\
\text { ATCC } 33849\end{array}$ \\
\hline Size, mb & 2.70 & 3.20 & 1.20 & 1.02 & 0.65 & 0.16 & 2.40 & 3.60 & 4.63 \\
\hline$G+C \%$ & 51.0 & 57.9 & 34.0 & 31.6 & 26.4 & 16.6 & 43.1 & 64.3 & 50.8 \\
\hline ORFs & 2757 & 4182 & 1118 & 981 & 615 & 213 & 2263 & 3317 & 4273 \\
\hline Average ORF length, bp & 885 & 354 & 874 & 897 & 935 & 737 & 974 & 1005 & 940 \\
\hline Percent coding & 90.7 & 69.8 & 79.8 & 85.9 & 87.6 & 97.3 & 90.5 & 90.6 & 86.6 \\
\hline rRNA operons (16S-23S-5S) & 1 & 1 & 1 & 1 & 1 & 1 & 3 & 3 & 7 \\
\hline tRNA genes & 38 & 32 & 36 & 36 & 32 & 28 & 43 & 51 & 88 \\
\hline Proteins with predicted function & 1988 & 2218 & 932 & 838 & 561 & 113 & 1785 & 2505 & 3506 \\
\hline $\begin{array}{r}\text { Hypothetical and uncharacterized } \\
\text { conserved proteins }\end{array}$ & 769 & 3693 & 175 & 253 & 106 & 46 & 689 & 924 & 833 \\
\hline ORFs in paralogous families & 382 & 292 & 27 & 19 & 7 & 0 & 159 & 413 & 794 \\
\hline Pseudogenes & 0 & 0 & 100 & 2 & 1 & 0 & 8 & 81 & 178 \\
\hline Sigma factors & 9 & 4 & 2 & 2 & 2 & 0 & 6 & 6 & 7 \\
\hline Mobile elements & 78 & 10 & 0 & 0 & 0 & 0 & 10 & 19 & 39 \\
\hline & Symbiont & Symbiont & Symbiont & Symbiont & Symbiont & Symbiont & Free-living & Free-living & Free-living \\
\hline
\end{tabular}

The comparison includes genomes of the chemosynthetic symbionts of R. pahyptila, C. magnifica, and C. okutanii; a symbiont of psyllids (the smallest sequenced genome), Carsonella ruddii; an a-proteobacterial aphid symbiont, B. aphidicola; free-living sulfur-oxidizers, T. crunogena and A. vinosum, and enterobacterium E. coli. *NCBI Accession PRJNA16744 and PRJNA72967. 


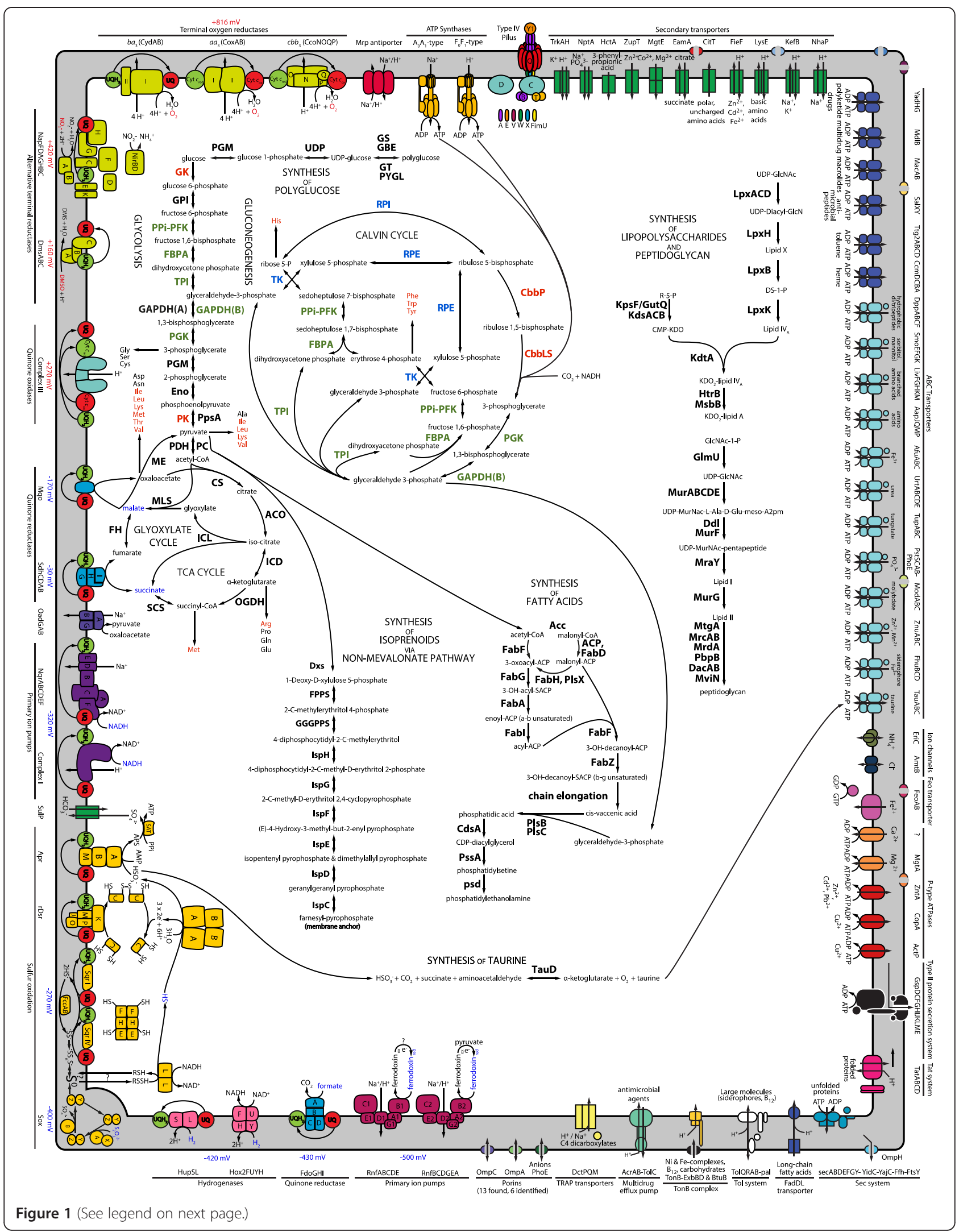


(See figure on previous page.)

Figure 1 Predicted model of the $\boldsymbol{S}$. velum symbiont cell. The diagram, based on the gene annotation of the symbiont genome, depicts key functional systems and metabolic pathways: sulfur oxidation, electron transport, ATP synthases, $\mathrm{CO}_{2}$-fixation via the Calvin Cycle, gluconeogenesis, polyglucose synthesis, glycolysis, TCA and glyoxylate cycles, synthesis of amino acids, fatty acids, lipids, isoprenoids via non-mevalonate pathway, and the cell wall, solute transporters, protein secretion systems, and the type IV pilus. Different protein categories are color-coded and the individual subunits indicated by shape symbols. The direction of substrate transport across the membrane is shown with arrows. Components of the electron transport chain are arranged from the lowest to the highest electronegativity of the electron donors (blue) and acceptors (red). The corresponding electronegativity values are listed next to the respective enzymes. Enzymes shared between glycolysis, gluconeogenesis, and the Calvin cycle are designated in green. Enzymes unique to these pathways are designated in red. Enzymes shared between the Calvin cycle and the pentose phosphate cycle are designated in blue. Amino acids which may be essential for the host are designated in red. Speculated pathways are designated with a question mark. The abbreviations used, the respective full gene product names, and the corresponding NCBI protein ID references are listed in Additional file 3: Table S3.

operon (Figure 4). While multiple homologues of $d s r C$ were identified outside the $d s r$ operon, these genes did not encode the two conserved C-terminal cysteines required for the protein to function $[48,49]$. The DsrC enzyme likely mediates transfer of electrons from sulfide reductase, DsrAB, to a transmembrane electron transport complex DsrKMJOP, an entry point for electrons derived from cytoplasmic oxidation of sulfur into the electron transport chain [50]. rDsr may be the key energy-generating pathway in the symbiont, as sulfide has a six-fold higher effect on carbon fixation in the $S$. velum symbiosis [13] compared to thiosulfate oxidized by the Sox pathway.
Sulfite oxidation Sulfite generated by rDsr may be further oxidized to sulfate in the cytoplasm by a sequential action of APS reductase (AprABM) and an ATP-generating ATP sulfurylase (Sat) (Figures 1 and 4). Identification of the respective genes agrees with measured Apr and Sat activity in the symbiont-containing S. velum tissue [51]. Sulfate generated in this pathway may be exported from the cytoplasm via a sulfate-bicarbonate antiporter SulP (Figure 1). While electrons obtained from the oxidation of sulfide, thiosulfate, and, possibly, elemental sulfur by Sox and rDsr are shuttled into the electron transport chain, energy obtained from the oxidation of sulfite is immediately available in the form of ATP.

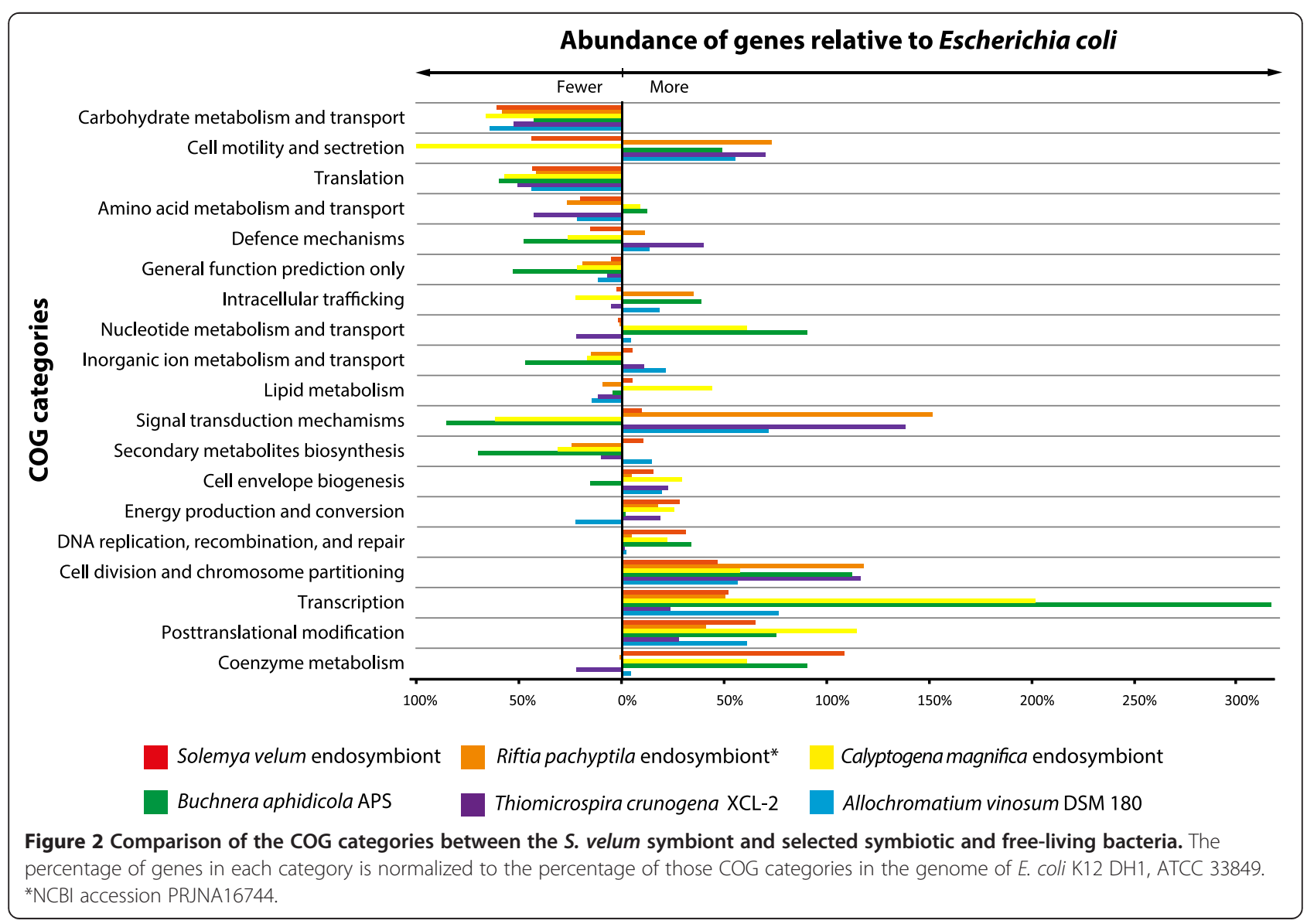




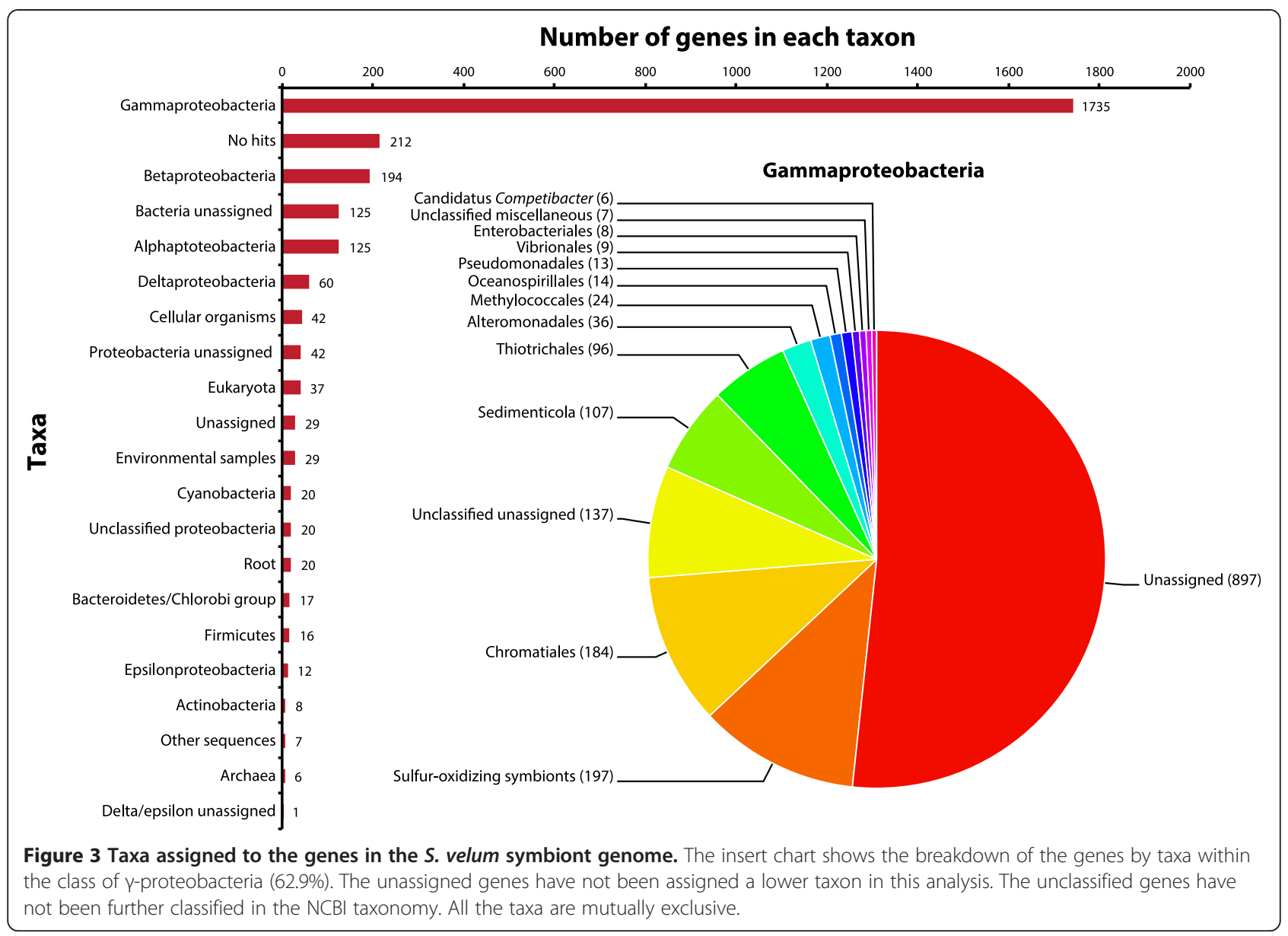

\section{Bioenergetics}

The $S$. velum symbiont is thought to harvest energy from reduced sulfur oxidation with oxygen. Interestingly, its genome also encodes other respiratory pathways suggestive of diverse metabolic strategies. Based on the gene content, the symbiont may utilize multiple electron donors such as hydrogen, pyruvate, malate, succinate, and formate, and use alternative electron acceptors such as nitrate and dimethyl sulfoxide (DMSO). Furthermore, unlike any chemosynthetic symbiont studied to date, the $S$. velum symbiont contains genes that may allow it to preferentially establish $\mathrm{H}^{+}$and $\mathrm{Na}^{+}$electrochemical membrane gradients during each step of respiration and to selectively utilize them for ATP synthesis, solute transport, and $\mathrm{pH}$ control. This high degree of respiratory flexibility encoded in the $S$. velum symbiont genome suggests that this bacterium is adapted to a highly variable environment.

Rnf complexes The versatile electron transport chain of the $S$. velum symbiont may utilize electron donors like ferrodoxins, which have a redox potential as negative as $-500 \mathrm{mV}$ [52], compared, for example, to $-400 \mathrm{mV}$ of $\mathrm{S}_{2} \mathrm{O}_{3}{ }^{2-}$ and $-270 \mathrm{mV}$ of $\mathrm{H}_{2} \mathrm{~S}$. The reversible oxidation of ferrodoxins coupled to the reduction of $\mathrm{NAD}^{+}$in the $S$. velum symbiont may be catalyzed by the $\mathrm{H}^{+}$or/and $\mathrm{Na}^{+}$-motive Rnf complexes (Figure 1) encoded in the genome by two complete $r n f A B C D G E$ ( $r n f 1)$ and $r n f B C D G E A$ $(r n f 2)$ operons. The organization of these genes in the operons is conserved with other bacteria, suggesting that these clusters did not arise from duplication. Previously, only Axotobacter vinelandii and Desulfobacterium autotrophicum were known to harbor two rnf operons [52]. Based on the presence of genes for pyruvate:ferredoxin oxidoreductase located between $r n f B 2$ and $r n f C 2$, pyruvate may serve as an electron donor for at least one of the Rnf complexes. In general, $r n f$ genes are distributed mainly among obligate and facultative anaerobes, including many pathogens that colonize oxygen-limited host tissues [52]. Together with the fact that ferrodoxins play a key role in anaerobic metabolism [53], this suggests that the S. velum symbiont, as well as other sequenced chemosynthetic symbionts, which all contain $r n f$ genes, may be capable of facultative anaerobiosis. 


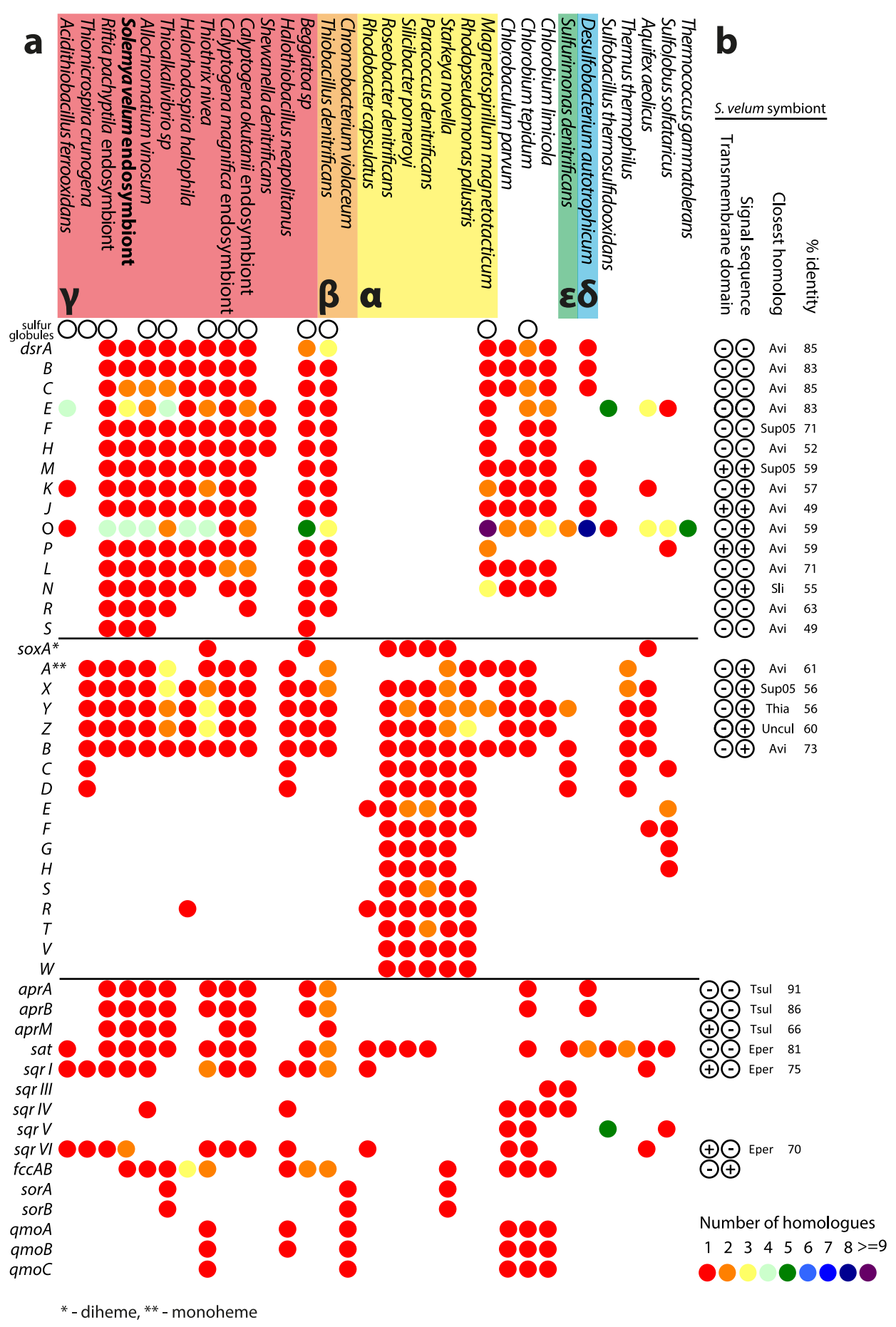

Figure 4 Comparison of the sulfur oxidation genes between the S. velum symbiont and other SOB. (a) Presence of genes involved in chemotrophic sulfur oxidation in the symbionts of $S$. velum, other sulfur-oxidizing bacteria and archaea, and sulfate reduction in D. autotrophicum, which is included for comparison. Genes encoding pathways for reverse-acting dissimilatory sulfur-oxidation (rDsr) (Drs in D. autotrophicum) and periplasmic sulfur-oxidation (Sox), as well as auxiliary proteins, are listed. Numbers of gene homologs in each organism are designated with color. Presence of extra- or intracellular sulfur deposits, i.e., globules, in each organism, as obtained from literature, is indicated with hollow circles. The abbreviations used, the respective full gene product names, and the corresponding NCBI protein ID references in the genome of the S. velum symbiont are listed in Additional file 3: Table S3. (b) Presence of signal sequences and transmembrane domains in the sulfur-oxidations genes of the S. velum symbiont, followed by the list of organisms with the closest known homologs to those genes and their respective BLASTP \% identities (Avi - Allochromatium vinosum, Sup05 - uncultivated oxygen minimum zone microbe [42], Sli - Sideroxydans lithotrophicus, and Thia - Thiocapsa marina, Uncul - uncultured organism, Tsul - Thioalkalivibrio sulfidiphilus, Eper - R. pachyptila endosymbiont). 
Hydrogenases Hydrogen is another highly electron negative reductant $(-420 \mathrm{mV})$ that the $S$. velum symbiont may harness for the reduction of the quinone and the $\mathrm{NAD}^{+}$cellular pools (Figure 1). Hydrogen oxidation is suggested by the presence in the symbiont genome of hup and hox 2 operons encoding an uptake and a bidirectional hydrogenase, respectively. The two subunits of the symbiont $[\mathrm{Ni}-\mathrm{Fe}]$-uptake hydrogenase, HupSL, are most similar in amino acid sequence to HupS and HupL proteins from the symbionts of the tubeworms, $R$. pachyptila and the $T$. jerichona, $(73 \%$ and $78 \%$ identity for the $\mathrm{S}$ and $\mathrm{L}$ subunits respectively), the sulfur bacterium, Thiocapsa roseopersicina, (68 and $74 \%$ ), and the symbionts of the scaly-foot snail, C. squamiferum, (50 and 53\%). In T. roseopersicina, HupSL has been experimentally demonstrated to reduce quinones of the respiratory chain with $\mathrm{H}_{2}$ $[54,55]$. Unlike all the other $\gamma$-proteobacteria containing HupSL, the hup operon in the $S$. velum symbiont does not encode the di-heme cytochrome $b$, which is necessary to link $\mathrm{H}_{2}$ oxidation to quinone reduction in the cellular membrane [56]. However, a [Ni-Fe] hydrogenase cytochrome $b$ homolog was found on a different genomic scaffold. Though this discordant gene organization is unlike that in other $\mathrm{H}_{2}$ oxidizers, it is possible that the identified cytochrome $b$ may act in tandem with HupSL to enable $\mathrm{H}_{2}$ oxidation.

Apart from potentially reducing the respiratory quinone pool with $\mathrm{H}_{2}$, the symbiont, by means of a bidirectional hydrogenase, may produce $\mathrm{H}_{2}$ by oxidizing $\mathrm{NAD}^{+}$. The $S$. velum symbiont Hox2FUYH enzyme complex is most similar in amino acid sequence (63-66\%) to the recently-characterized $\mathrm{NAD}^{+}$-reducing $[\mathrm{Ni}-\mathrm{Fe}]$-hydrogenase from $T$. roseopersicina, which can operate in reverse, generating $\mathrm{H}_{2}$ when the high reduction state of the dinucleotide pool is growth-limiting [57]. As $\mathrm{H}_{2}$ concentrations available to the $S$. velum symbiont have not been measured, it is unknown whether the $\mathrm{H}_{2}$ oxidation contributes to primary production to the degree that has been recently demonstrated in a hydrothermal vent symbiosis [58].

Primary ion pumps NADH $(-320 \mathrm{mV})$, potentially derived from oxidation of $\mathrm{H}_{2}$ or heterotrophic metabolism (see Heterotrophy) in the S. velum symbiont, could be converted into an electrochemical gradient by two NADH:quinone oxidoreductases. The genome of the symbiont encodes the conventional $\mathrm{H}^{+}$-translocating quinone-reducing $\mathrm{NADH}$ dehydrogenase (NdhABCDEFGHIJKLMN), a homolog of the mitochondrial Complex I, as well as an alternative $\mathrm{Na}^{+}$-translocating NADH dehydrogenase (NqrABCDEF) (Figure 1). While Complex I is ubiquitous in bacteria, Nqr is found mainly in pathogenic and marine species [59]. Among symbiotic bacteria, $n q r$ genes have so far been described only in
Buchnera spp., an obligate endosymbiont of aphids [60]. The S. velum symbiont may be able to switch between Complex I and Nqr, preferentially generating either $\mathrm{H}^{+}$or $\mathrm{Na}^{+}$electrochemical gradients. Thus, depending on the cellular requirements, the symbiont may synthesize ATP (see ATP synthases) and regulate $\mathrm{pH}$ (see Ion gradient driven transporters) independently from each other.

Quinone reductases Apart from the electron donors such as sulfur and NADH, the S. velum symbiont may be able to directly reduce its quinone pool with a number of other substrates. This is suggested by the presence of genes encoding malate:quinone oxidoreductase (Mqo), succinate dehydrogenase (ShdCDAB), homologous to Complex II in mitochondria, and formate dehydrogenaseO (FdoGHI) (Figure 1). This is the first report of FdoGHI in a chemosynthetic symbiont genome. In $E$. coli this enzyme, which is common to facultative anaerobes [61], is used in formate-dependent oxygen respiration, allowing the bacteria to rapidly adapt to shifts from aerobiosis to anaerobiosis [62]. The presence of FdoGHI is additional evidence that the $S$. velum symbiont may be capable of facultative anaerobiosis (see Rnf complexes).

The genome-encoded quinol-cytochrome- $c$ oxidoreductase ( $b c_{1}$, Complex III homologue) potentially links oxidation of quinols to the generation of a proton membrane gradient and the reduction of terminal electron acceptors (Figure 1), discussed next.

Terminal oxygen reductases Similar to most aerobic and microaerophilic bacteria, the genome of the S. velum symbiont encodes three types of $\mathrm{H}^{+}$-motive terminal oxygen reductases (Figure 1), which suggest a capacity to respire $\mathrm{O}_{2}$ over a wide range of concentrations. The genome contains a $c c o N O Q P$ operon encoding a $c b b_{3}$ cytochrome oxidase, which is known to function at nanomolar $\mathrm{O}_{2}$ concentrations in the nitrogen-fixing plant symbionts, Bradyrhizobium japonicum [63], and in the microaerophilic human pathogens, Campylobacter jejuni, Helicobacter pylori, and Neisseria meningitidis [64]. The genome also encodes a $a a_{3}$ cytochrome oxidase (CoxAB), which is thought to function primarily under atmospheric oxygen concentrations [65] and is the only terminal oxidase in the symbionts of the bivalves C. magnifica [22] and C. okutanii [20]. The third terminal oxidase identified in the symbiont genome is a $c y d A B$-encoded quinol oxidase, which is thought to oxidize quinols instead of cytochromes. $\mathrm{Cyd} A \mathrm{~B}$ may operate when an excess of reductants, potentially coming from the host, limits metabolic turnover and a redox balance needs to be achieved [66]. The observed diversity of terminal oxygen reductases indicates that the supply of oxygen to the symbionts may fluctuate over time or between free-living and symbiotic stages, necessitating adjustments in respiratory metabolism. 
Alternative terminal reductases When oxygen is limited or unavailable, potentially either through competition for oxygen with the host or if the symbionts find themselves in the anoxic sediment that surrounds the burrow, the $S$. velum symbiont may be capable of using terminal electron acceptors other than oxygen. Although it is unknown whether the symbiont-containing gill bacteriocytes ever become anaerobic, the presence of genes for periplasmic $\mathrm{NO}_{3}^{-}$reductase (napFDAGHBC) suggests that symbiont energy generation may involve electron transfer to nitrate, which is available in the porewater surrounding S. velum at concentrations of $\sim 1-10 \mu \mathrm{M}$ ([67], in preparation). The structure of the symbiont napFDAGHBC operon is consistent with that of enteric bacteria that are thought to use Nap for effectively scavenging nitrate during anaerobic growth under nitrate-limited conditions $(5 \mu \mathrm{M})$ [68]. The symbiont genome also encodes a DMSO reductase $(d m s A B C)$, which suggests an ability to respire dimethyl sulfoxide (DMSO), a breakdown product of dimethylsulfoniopropionate (DMSP) produced, for example, by marine algae. DMSO is available at nanomolar concentrations in the coastal eutrophic environments inhabited by S. velum [69], and Dms genes are common to many marine sediment-dwelling bacteria, e.g., Beggiatoa and Shewanella $[70,71]$.

ATP synthases Based on the genome data, both $\mathrm{H}^{+}$and $\mathrm{Na}^{+}$membrane gradients, established along the course of the electron transport chain during respiration, may drive ATP synthesis in the S. velum symbiont via either $\mathrm{H}^{+}$or $\mathrm{Na}^{+}$-dependent ATP synthases (Figure 1). The $\mathrm{H}^{+}$-specificity of the $\mathrm{F}_{0} \mathrm{~F}_{1}$-type ATP synthase is suggested by the presence of two characteristic transmembrane helixes within the $c$ subunit. In contrast, an $\mathrm{A}_{0} \mathrm{~A}_{1}$-type ATP synthase detected in the genome contains the characteristic $\mathrm{Na}^{+}$-binding PXXXQ motif I and ES motif II in the rotor subunit $\mathrm{K}$. While proton-translocating ATP synthases are predominant in bacteria, $\mathrm{Na}^{+}$-coupled ATP synthesis driven by respiration has recently been recognized in some marine and pathogenic species [72,73]. To our knowledge, this is the first report of a $\mathrm{Na}^{+}$-translocating ATP synthase in a chemosynthetic symbiont.

Ion gradient driven transporters Cellular roles of the $\mathrm{H}^{+}$and $\mathrm{Na}^{+}$gradients in the S. velum symbiont appear to extend beyond ATP synthesis. Besides ATP synthases, the genome encodes diverse $\mathrm{Na}^{+}$:substrate symporters and numerous $\mathrm{Na}^{+}: \mathrm{H}^{+}$antiporters, including the multisubunit MrpEFGBBCDD complex (Figure 1). These transporters, together with ATP synthases and respiratory ion pumps, may establish and consume simultaneous transmembrane gradients of protons and sodium ions in the symbiont [72]. These parallel cycles of $\mathrm{H}^{+}$and $\mathrm{Na}^{+}$would allow the $S$. velum symbiont to synthesize ATP and maintain $\mathrm{pH}$ homeostasis via two separate mechanisms.

\section{Carbon metabolism}

Autotrophic carbon fixation, fueled chiefly by sulfur oxidation, is the principal process in the S. velum symbiont, supplying both the symbiont and the host with organic carbon [14]. While previous studies focused primarily on RuBisCO $[10,74]$, the key enzyme of the Calvin cycle for $\mathrm{CO}_{2}$ fixation and the most highly expressed gene in the symbiont [40], our current analysis identified genes that encode catalytic components required for $\mathrm{CO}_{2}$ fixation and storage, including the pyrophosphate-dependent phosphofructokinase, which has been hypothesized to command a more energy efficient variant of the cycle [22,75-77]. Furthermore, the genome of the S. velum symbiont contains the gene for $\alpha$-ketoglutarate dehydrogenase - the key enzyme of the tricarboxylic acid cycle (TCA), suggesting that the symbiont can respire organic carbon and may not be obligately autotrophic.

Autotrophy The genome of the S. velum symbiont encodes a version of the Calvin cycle which appears to be prevalent in chemosynthetic symbionts but may also operate in a few free-living bacteria [75-77]. In these organisms genes for fructose 1,6-bisphosphatase and sedoheptulose 1,7bisphosphatase, which process obligate intermediates in the cycle, are absent. Instead, the role of the missing enzymes may be performed by a single reversible pyrophosphate-dependent phosphofructokinase (PPi-PFK), the gene for which was identified in the genome of the $S$. velum symbiont (Figure 1). The ability of this enzyme to dephosphorylate fructose 1,6-bisphosphate and sedoheptulose 1,7-bisphosphate in vitro was demonstrated for the PPi-PFK from Methylococcus capsulatus [75], which shares $73 \%$ amino acid sequence identity with the homologue from the S. velum symbiont. Notably, during dephosphorylation this enzyme generates pyrophosphate, which bears a high-energy phosphate bond unlike the orthophosphate liberated by fructose 1,6-bisphosphatase and sedoheptulose 1,7-bisphosphatase. In $M$. capsulatus [75] and in the chemosynthetic symbionts of R. pachyptila [76] and the oligochete, O. algarvensis [77], it was proposed that the pyrophosphate produced this way could be converted into a proton gradient by a membrane-bound proton-pumping pyrophosphatase (V-type $\mathrm{H}^{+}$-PPase) coencoded with the PPi-PFK. This proton gradient could then be used for ATP synthesis. Compared to the classical Calvin cycle [78], this mechanism may allow bacteria to spend up to $9.25 \%$ less energy on $\mathrm{CO}_{2}$ fixation [77]. Judging from the similar gene content, this version of the cycle may also be at work in the symbionts of the vent clams, $C$. magnifica [22] and C. okutanii [20]. Apart from the membrane-bound V-type $\mathrm{H}^{+}$-PPase, the $S$. velum symbiont 
genome also encodes a soluble pyrophosphatase (PPase) immediately upstream of the PPi-PFK gene. The PPase cannot convert the energy of pyrophosphate into a proton gradient but, by controlling the availability of pyrophosphate, may serve to regulate the catalytic direction of the PPi-PFK, which may also participate in glycolysis as a kinase. This additional PPase suggests that it may be important for the $S$. velum symbiont to control the direction of its carbon flux to a higher degree than what has been seen in other chemosynthetic symbionts.

Carbon Flux Carbon fixed by the $S$. velum symbiont may be stored as polyglucose or fed into catabolic and anabolic reactions (Figure 1). The overall direction of the metabolic carbon flux in the symbiont can be controlled by at least two putative mechanisms. First, the reversible PPi-PFK, participating in the Calvin cycle as discussed above, may also phosphorylate fructose 6-phosphate during glycolysis. PPi-PFK appears to be the only enzyme encoded in the genome that could catalyze both the forward and the reverse reactions. The directionality of the catalysis may depend on the concentration of pyrophosphate and the other substrates of the enzyme in the cytoplasm [79], since this PPi-PFK is likely nonallosteric [75]. Second, the two encoded glyceraldehyde 3-phosphate dehydrogenases, GapA and GapB, may be specific to glycolysis and the Calvin cycle/gluconeogenesis, respectively, by analogy to the homologous enzymes in Staphylococcus aureus [80]. In the symbiont genome, gapB is adjacent to the gene for transketolase, an enzyme in the Calvin cycle, further suggesting that these two Gap proteins may play a role in regulating the direction of the carbon flux either in the direction of glycolysis or the Calvin cycle and gluconeogenesis. The symbionts of C. magnifica, C. okutanii, $R$. pachyptila, T. jerichona, and the scaly snail possess just a single gap gene, which has a much higher amino acid sequence identity to gapB than to gapA from the $S$. velum symbiont. In line of the above evidence the symbiont of $S$. velum appears to be distinct from other chemosynthetic symbionts in placing a stronger emphasis on controlling the direction of its carbon flux.

Heterotrophy The S. velum symbiont is the third chemosynthetic symbiont, along with the $\gamma 3$-symbiont of $O$. algarvensis [34] and the intracellular $\gamma$-proteobacterial symbionts of the scaly-foot snail [33], known to encode all of the enzymes required for the complete TCA cycle, and, therefore, could oxidize organic carbon for energy (Figure 1). All of the other sequenced chemosynthetic symbionts lack genes for $\alpha$-ketoglutarate dehydrogenase and citrate synthase, which suggests their obligate autotrophy [81].

Furthermore, genes for the glyoxylate bypass of the TCA cycle, encoding isocitrate lyase and malate synthase, were also found in the genome of the $S$. velum symbiont (Figure 1). These enzymes could allow the symbiont to grow on various carbon sources, including acetate and other two-carbon compounds, [82] or rapidly replenish intermediates of biosynthetic reactions. The presence of the glyoxylate bypass and the TCA cycle suggests that the symbiont may be a facultative mixo- or heterotroph. The adaptive role of having both heterotrophic pathways, however, is unclear, and may relate either to the intracellular conditions specific to this particular symbiosis or to the yet unconfirmed host-free existence of the symbiont.

\section{Nitrogen metabolism}

Ammonia, abundant in the sediment where $S$. velum burrows, is the main form of nitrogen assimilated by the symbiosis [83]. It has been suggested that the symbionts incorporate ammonia into biomass, which is then transferred to the host ([67] in preparation), a process which has been described for the chemosynthetic symbionts of the hydrothermal vent tubeworm Ridgeia piscesae [84]. The presence of assimilatory nitrogen pathways in the $S$. velum symbiont genome corroborate this hypothesis.

Nitrogen assimilation Extracellular ammonia may be imported by the symbiont via specific $A m t B$ transporters and incorporated into glutamate and glutamine, which serve as amino group donors for the other nitrogencontaining compounds in the cell (Figure 1). The S. velum symbiosis comes in contact with $20-100 \mu \mathrm{M}$ concentration of ammonia in its coastal environment ([67] in preparation). Thus, it is not surprising that, unlike the chemosynthetic symbionts found at nitrate-rich $(40 \mu \mathrm{M})$ hydrothermal vents $[85,86]$, the $S$. velum symbiont lacks nar genes for nitrate reductases capable of assimilatory nitrate reduction [32,87-89]. Assimilation of ammonia has been previously demonstrated in the gills of $S$. velum, but was initially ascribed to the activity of the host glutamine synthetase (GS) [88]. The present analysis identified $g \ln A$, the gene that encodes GS, in the genome of the symbiont. A preliminary transcriptional study showed $g \ln A$ to be one of the fifty most highly transcribed genes in the symbiont [40]. The biosynthetic pathways reconstructed on the basis of gene content suggest that the symbiont has the ability to make all of the 20 proteinogenic amino acids. The amino acid prototrophy of the symbiont is in keeping with its proposed role in providing most, if not all, of the host's nutrition $[14,15]$.

Urea metabolism Host urea may serve as an additional source of assimilatory nitrogen for the $S$. velum symbiont. The identified ureHABCEFG operon encodes a cytoplasmic urease Ure $A B C$, which can hydrolyze urea, releasing 
ammonia that may be re-utilized by the symbiont. Urea can enter the bacterial cell by passive diffusion [90], but under nitrogen starvation the symbiont may be able to take it up more rapidly via an $\mathrm{ABC}$-transporter UrtABCDE, encoded directly upstream of the ure genes. Among chemosynthetic symbionts, urease genes have been previously described only in the $\gamma$-symbionts from the marine oligochaete worm $O$. algarvensis [34,77], which, like S. velum, lives in coastal sediments. The sequenced chemosynthetic symbionts from hydrothermal vents lack urease genes, even though some of their host organisms, for instance R. pachyptila [91], are known to produce urea. This discrepancy may be accounted for by the fact that in coastal sediments urea is also present outside the host in the pore water ([67] in preparation).

Taurine synthesis The $S$. velum symbiont may also provide its host with nitrogenous osmoregulants, such as the non-proteinogenic amino acid taurine [92]. In the host tissues, taurine accounts for up to $70 \%$ of the total free amino acids and shows an isotopic composition $\left(\delta^{13} \mathrm{C}, \delta^{14} \mathrm{~N}, \delta^{34} \mathrm{~S}\right)$ suggestive of symbiont origin [93]. Synthesis of taurine may be accomplished by the two homologs of the reversible taurine dioxygenase (TauD) encoded in the symbiont genome. Taurine could be actively secreted to the host by the TauABCD ABC transporter, the genes for which were found to contain a conserved binding domain for sulfonate, characteristic of the taurine molecule. Since taurine synthesis requires sulfite [94], one of the final intermediates in sulfur oxidation, this pathway could serve to dispose of $\mathrm{SO}_{3}{ }^{2-}$, and, thus, to drive forward sulfur oxidation in the $S$. velum symbiont, benefiting both the host and the symbiont.

\section{Membrane-associated functions}

The diversity of membrane-associated functions encoded in the genome of the $S$. velum symbiont suggests that the symbiont is fully autonomous of its host in this aspect of its physiology. Other bacteria, which, like the symbiont, are thought to be obligately intracellular [17], have lost genes required for the production of a cellular envelope, transport of solutes across the plasma membrane, sensing of the extracellular environment, as well as motility. These bacteria instead rely on their hosts to perform these functions or no longer require them.

\section{Production of cellular envelope}

The S. velum symbiont appears capable of synthesizing and assembling a cytoplasmic membrane, a peptidoglycan layer (PG), and an outer membrane populated by lipopolysaccharides (LPS), which constitute a cellular envelope. While these abilities are typical of the free-living $\gamma$-proteobacteria, two aspects in particular stand out in the context of the symbiotic life-style. First, given the identified genes for the biosynthesis of fatty-acids, the symbiont may build components of its plasma membrane mostly from cis-vaccenic acid (18: $1 \omega 7$ ) (Figure 1). According to a previous analysis of lipid composition in S. velum [95], this unsaturated fatty acid and its derivatives are the main constituents of cellular membranes in the symbiont and the host alike. Furthermore, the isotopic signature of the host's lipids indicates that they are bacterial in origin [95]. Second, the identified genes for the synthesis of lipopolysaccharides (Figure 1) suggest that the symbiont may be able to assemble the LPS structures that are known to be sufficient for growth of E. coli [96]. Most intracellular symbionts that live within a host derived membrane, like the $S$. velum symbiont [10], lack LPS biosynthetic genes and are unable to replicate on their own [97]. However, the symbionts which have the genes to synthesize LPS tend to either live directly in the cytoplasm [97] and have to make their own cellular envelope or, like the symbionts of $R$. pachyptila [98], exist extracellularly for part of their life. Therefore, the symbiont of $S$. velum may not only be able to make a fully functional cellular envelope and supply some of its components to its host, but may also be capable of living outside the bacteriocytes.

\section{Membrane transport}

Transporters The number of transporters encoded in the genome of the S. velum symbiont exceeds what has been found in other intracellular bacteria (Table 2). The diversity of genes for solute transport (Figure 1) suggests that the symbiont has an extensive chemical communication with their environment. The S. velum symbiont may use these transporters to import metabolic substrates and enzyme cofactors and export products of its biosynthesis to sustain the physiology of the host. It is known that fixed organic carbon is transferred from the symbiont to the host within minutes [99], which suggests a transport mechanism, since direct digestion of symbionts by host cells would likely take hours to days [100]. Such transport could be accomplished by exporters of amino acids (EamA), carboxylates (CitT), and fatty acids (FadLD), all of which are encoded in the genome. Moreover, some of the importers found in the genome may also act as exporters, depending on the cellular environment [101]. Thus, the $S$. velum symbiont maintains a repertoire of transporters that may negotiate diverse chemical exchanges with the environment and, on the other hand, allow it to provide nutrients to the host without being digested.

Multi-drug efflux pumps The S. velum symbiont genome contains at least five sets of genes encoding multi-drug efflux pumps (AcrAB-TolC), suggesting the ability to expel 
Table 2 Comparison of extracellular transport genes in the S. velum symbiont, other symbiotic and free-living bacteria

\begin{tabular}{|c|c|c|c|c|c|c|c|c|c|c|c|c|}
\hline Organism & Lifestyle & $\begin{array}{l}\text { Transporter } \\
\text { gene ratio to } \\
\text { S. velum } \\
\text { endosymbiont }\end{array}$ & $\begin{array}{l}\text { Genome } \\
\text { size }(\mathrm{Mb})\end{array}$ & $\begin{array}{l}\text { Total number } \\
\text { of genes } \\
\text { involved in } \\
\text { transport }\end{array}$ & $\begin{array}{l}\text { Transporter } \\
\text { genes per } \\
\text { Mb of } \\
\text { genome }\end{array}$ & $\begin{array}{c}\text { ATP- } \\
\text { dependent } \\
\text { transporters }\end{array}$ & $\begin{array}{l}\text { Secondary } \\
\text { transporters }\end{array}$ & $\begin{array}{l}\text { Phosphotransferase } \\
\text { systems }\end{array}$ & $\begin{array}{l}\text { lon } \\
\text { channels }\end{array}$ & $\begin{array}{l}\text { Unclassified } \\
\text { transporters }\end{array}$ & $\begin{array}{l}\text { Protein } \\
\text { secretion } \\
\text { systems }\end{array}$ & $\begin{array}{c}\text { Outer } \\
\text { membrane } \\
\text { transporters }\end{array}$ \\
\hline $\begin{array}{l}\text { Solemya velum } \\
\text { endosymbiont }\end{array}$ & $\begin{array}{r}\text { Intracellular } \\
\text { symbiont }\end{array}$ & 1.00 & 2.7 & 224 & 75.2 & 100 & 70 & 1 & 5 & 5 & 17 & 26 \\
\hline $\begin{array}{r}\text { C. magnifica } \\
\text { endosymbiont }\end{array}$ & OIS* & 0.14 & 1.16 & 32 & 27.6 & 18 & 6 & 0 & 3 & 1 & 0 & 4 \\
\hline $\begin{array}{r}\text { C. okutanii } \\
\text { endosymbiont }\end{array}$ & OIS & 0.15 & 1.02 & 34 & 33.3 & 16 & 10 & 0 & 2 & 3 & 0 & 3 \\
\hline $\begin{array}{r}\text { Buchnera } \\
\text { aphidicola APS }\end{array}$ & OIS & 0.07 & 0.64 & 16 & 25.0 & 5 & 3 & 5 & 1 & 0 & 0 & 2 \\
\hline Sulcia muelleri GWSS & OIS & 0.03 & 0.25 & 7 & 28.0 & 4 & 2 & 0 & 0 & 0 & 0 & 1 \\
\hline $\begin{array}{r}\text { Ca. Blochmannia } \\
\text { floridanus }\end{array}$ & OIS & 0.12 & 0.71 & 27 & 38.0 & 7 & 12 & 3 & 2 & 0 & 0 & 3 \\
\hline $\begin{array}{r}\text { Wigglesworthia } \\
\text { glossinidia }\end{array}$ & OIS & 0.11 & 0.70 & 25 & 35.7 & 9 & 14 & 0 & 2 & 0 & 0 & 0 \\
\hline $\begin{array}{r}\text { Baumannia } \\
\text { cicadellinicola }\end{array}$ & OIS & 0.13 & 0.69 & 28 & 40.6 & 11 & 10 & 3 & 1 & 0 & 0 & 3 \\
\hline $\begin{array}{l}\text { R. leguminosarum } \\
\text { bv. Viciae } 3841\end{array}$ & FIS* & 2.47 & 7.75 & 553 & 71.4 & 281 & 203 & 7 & 18 & 2 & 13 & 29 \\
\hline Frankia alni ACN14a & FIS & 1.05 & 7.50 & 236 & 31.5 & 114 & 106 & 0 & 12 & 1 & 1 & 4 \\
\hline $\begin{array}{r}\text { Vibrio fischeri } \\
\text { MJ11 }\end{array}$ & $\begin{array}{r}\text { Extracellular } \\
\text { symbiont }\end{array}$ & 1.80 & 4.50 & 404 & 89.8 & 138 & 141 & 12 & 10 & 6 & 46 & 51 \\
\hline $\begin{array}{r}\text { Wolbachia } \\
\text { pipientis wSim }\end{array}$ & OIS/parasite & 0.21 & 1.06 & 48 & 45.3 & 19 & 28 & 0 & 0 & 1 & 8 & 0 \\
\hline $\begin{array}{r}\text { Rickettsia prowazekii } \\
\text { MadridE }\end{array}$ & $\begin{array}{l}\text { Intracellular } \\
\text { parasite }\end{array}$ & 0.21 & 1.10 & 48 & 43.6 & 15 & 30 & 0 & 1 & 1 & 0 & 5 \\
\hline $\begin{array}{c}\text { Escherichia coli } \\
\text { K-12-MG1655 }\end{array}$ & Commensal & 1.58 & 4.64 & 354 & 76.3 & 74 & 235 & 29 & 13 & 2 & 3 & 35 \\
\hline $\begin{array}{r}\text { Klebsiella pneumoniae } \\
\text { kp342 }\end{array}$ & Commensal & 2.82 & 5.92 & 632 & 106.8 & 160 & 336 & 44 & 17 & 4 & 37 & 34 \\
\hline $\begin{array}{r}\text { Thiomicrospira } \\
\text { crunogena XCL-2 }\end{array}$ & $\begin{array}{r}\text { Free-living } \\
\text { sulfide oxidizer }\end{array}$ & 0.73 & 2.43 & 163 & 67.1 & 38 & 58 & 0 & 10 & 3 & 35 & 19 \\
\hline $\begin{array}{l}\text { Allochromatium } \\
\text { vinosum DSM } 180\end{array}$ & $\begin{array}{r}\text { Free-living } \\
\text { sulfide oxidizer }\end{array}$ & 0.89 & 3.67 & 199 & 54.2 & 81 & 52 & 5 & 8 & 7 & 14 & 32 \\
\hline $\begin{array}{r}\text { Sulfurimonas } \\
\text { denitrificans } \\
\text { DSM } 1251\end{array}$ & $\begin{array}{r}\text { Free-living } \\
\text { sulfide oxidizer }\end{array}$ & 0.43 & 2.20 & 97 & 44.1 & 32 & 52 & 0 & 10 & 3 & 6 & 25 \\
\hline $\begin{array}{l}\text { Methylococcus } \\
\text { capsulatus Bath }\end{array}$ & $\begin{array}{r}\text { Free-living } \\
\text { methanotroph }\end{array}$ & 0.76 & 3.30 & 171 & 51.8 & 56 & 60 & 0 & 6 & 2 & 16 & 31 \\
\hline $\begin{array}{l}\text { Thermodesulfovibrio } \\
\text { yellowstonii DSM } 11347\end{array}$ & $\begin{array}{r}\text { Free-living } \\
\text { sulfate reducer }\end{array}$ & 0.39 & 2.00 & 88 & 44.0 & 31 & 34 & 0 & 3 & 2 & 3 & 15 \\
\hline
\end{tabular}


host-derived antimicrobial agents. A comparable genetic capacity for the AcrAB-TolC efflux system has been found in bacteria, such as the plant symbiont Rhizobium leguminosarum, that have a free-living stage, but not in bacteria that are obligately intracellular (Table 2, ATP-dependent transporters). The plant host of $R$. leguminosarum manipulates the cellular fate of its symbionts using antimicrobiallike peptide factors [102]. As a result, $R$. leguminosarum undergoes cell elongation and genome replication but looses its ability to divide. Only a small number of $R$. leguminosarum cells remain vegetative [103]. A very similar morphological differentiation of the symbiont has been observed in S. velum [104]. Assuming the bivalve host also uses peptide factors to control its symbiont, the $S$. velum symbiont may rely on the efflux pumps to maintain a small undifferentiated population in the bacteriocytes for transmission to future host generations.

\section{Sensory mechanisms and motility}

The $S$. velum symbiont appears well equipped to sense extracellular chemical changes, consistent with its inferred ability to maintain a complex chemical exchange with the environment. Over forty transmembrane chemoreceptors are encoded in the genome of the symbiont. Almost half of them have one or more conserved PAS domains and therefore may play a role in sensing oxygen levels and redox potentials. To relay sensory information, the majority of the receptors contain either a diguanylate cyclase (GGDEF) or a histidine kinase (HisKA) signaling domain. Movement and surface attachment using type IV pili, known as twitching motility, are the processes that may be regulated by chemosensory signal transduction in the S. velum symbiont (Figure 1). For example, in the genome of the symbiont a chimeric gene containing PAS, GGDEF, and cyclic-diguanylate receptor (EAL) domains is colocated with pilEY1XWVT genes required to assemble a functional pilus. Furthermore, the symbiont genome contains pilGIJ-che $A W$ genes, which encode a transmembrane chemotaxis sensor protein, HisKA, and a DNA-binding response regulator, and are known to control twitching motility in other bacteria [105]. The symbiont may use the contractile pili to direct its movement in the environment with regard to chemicals gradients, and, potentially, also rely on the same mechanism to find and colonize new hosts.

\section{Mobile genetic elements}

The $S$. velum symbiont genome contains two major types of mobile elements, integrative and conjugative elements (ICEs) and insertion sequences (IS). The genome contains 25 insertions from 12 different ICE families (Table 3) as well as 53 copies of four different IS elements (Table 4). In total, these elements comprise $2.6 \%$ of the genome. No gene interruptions were associated with these
Table 3 ICE mobile genetic elements in the S. velum symbiont genome

\begin{tabular}{lcc}
\hline ICE element & Copies & Length, bp \\
\hline ICEVchLao1 & 1 & 834 \\
ICEVchBan7 & 1 & 432 \\
ICEVchBan9 & 2 & 429,888 \\
ICEVchInd5 & 1 & 282 \\
ICEVchMex1 & 1 & 561 \\
ICEVflind1 & 2 & 405,729 \\
ICEPalBan1 & 1 & 1389 \\
ICEPdaSpa1 & 5 & $300,387,622,939,3568$ \\
ICESpuPO1 & 3 & $549,627,648$ \\
ICEPmiUSA1 & 1 & 1290
\end{tabular}

elements. This large number and diversity of mobile elements suggest that this bacterium may come into contact with other bacterial lineages more often than expected for most vertically transmitted intracellular symbionts. Indeed, the abundance of mobile genetic elements in bacterial genomes has been shown to correlate with ecological niche. While there is considerable overlap between the amounts of mobile elements hosted by free-living and facultative intracellular bacteria, obligate intracellular bacteria that undergo faithful vertical transmission consistently have few or no mobile elements [106].

Two hypothesized life and evolutionary history scenarios may explain the observed mobile element content in the $S$. velum symbiont. One of them is a relatively recent shift to intracellularity, resulting in an expansion of mobile elements $[107,108]$. Alternatively, the symbionts may undergo regular or occasional horizontal transmissions between hosts and at that time encounter opportunities for recombination between strains. For example, sporadic episodes of horizontal transmission in the primarily maternally transmitted insect symbiont, Wolbachia, have resulted in the acquisition and maintenance of novel mobile

Table 4 Insertion sequence mobile genetic elements in the $S$. velum symbiont genome

\begin{tabular}{cccc}
\hline Family/Element & Copies & Length, bp & Terminal inverted repeats \\
\hline IS30 & 30 & 1071 & ATTCAA \\
IS3/IS407 & 18 & 1219 & CCCCCA/CCCCCAA(C/T)AAGT \\
IS30 & 1 & 900 & CAACCGTTTCAAT \\
IS5/IS5 & 1 & 1638 & ACCCAAGGTA \\
IS481 & 1 & 1271 & GAGACATCATTTACA \\
IS30 & 1 & 1137 & TGATGTACGGGTCCGA \\
Unknown & 1 & 1848 & CCCCTTCG \\
\hline
\end{tabular}


elements [109,110]. In fact, horizontal transmission or host-switching has likely occurred in the history of symbionts of bivalves [111] including members of the genus Solemya, as 16S rRNA phylogenetic analyses show that these symbionts do not comprise a monophyletic clade [5,11]. Additionally, many of the genes in the $S$. velum symbiont genome are most closely related to disparate bacterial taxa (Figure 3), suggesting that horizontal gene transfer may have occurred in the past. These preliminary lines of evidence support the hypothesis that horizontal symbiont transmission has occurred. However, more information is needed about the distribution and relationships of the mobile elements among intra-host and inter-host $S$. velum symbiont populations before these hypotheses can be differentiated.

\section{Conclusions}

Many of the features commonly encoded in the genomes of chemosynthetic symbionts were observed in the genome of the $S$. velum symbiont alongside an array of genes unique to this bacterium. Potential adaptations to the symbiotic lifestyle, such as a more energy-efficient version of the Calvin cycle, were shared with the other sequenced chemosynthetic symbionts. The genes that set the $S$. velum symbiont apart from the others were those that encoded the TCA and the glyoxylate cycles, DMSO and urea reductases, as well as the highly branched electron transport chain. These functions may relate to the fact that the S. velum symbiosis lives in eutrophic sediment, unlike the oligotrophic environments inhabited by other chemosynthetic symbioses, e.g., those of $R$. pachyptila, C. magnifica, and O. algarvensis.

The $S$. velum symbiont has long been considered to be vertically transmitted [17], but our genomic analyses are inconsistent with predictions based on other vertically transmitted obligately-intracellular bacteria. The $S$. velum symbiont's genetic repertoire is replete with genes for chemosynthesis, heterotrophy, bioenergetics, nitrogen metabolism, cell maintenance, motility, communication, and exchange with the environment. Thus, with regard to the functional gene content, but also the genome size and GC composition, the genome is more similar to those of free-living sulfur-oxidizing bacteria (Table 1). Furthermore, the genome contains mobile elements that are comparable in numbers reported for horizontallytransmitted obligately-intracellular bacteria. These divergent lines of evidence suggest that the evolutionary life history of the $S$. velum symbiont may be more complicated than previously hypothesized. This could include, but may not be limited to, an opportunistic generalist lifestyle, a facultative symbiosis with a mixed transmission mode, or a very recent obligate association with the host for this clade of bacteria potentially on a path to a new type of a cellular organelle.

\section{Methods}

\section{Specimen collection and DNA preparation}

S. velum individuals were collected by the staff of the Marine Resource Center of the Marine Biological Laboratory (MBL), Woods Hole, MA from reducing sediment of shallow eelgrass beds near Naushon Island, Woods Hole, MA in 2006, 2007, and 2012. The collection was performed in accordance with state collecting permit issued by the Division of Marine Fisheries and in compliance with all local, regional and federal regulations, including the Convention on Biological Diversity and the Convention on the Trade in Endangered Species of Wild Fauna and Flora. The excised gills were macerated in the laboratory using a dounce homogenizer in $5 \mathrm{ml}$ of $0.2 \mu \mathrm{m}$ filtered seawater (FSW) per bivalve. Homogenates were passed through $100 \mu \mathrm{m}$ and $5 \mu \mathrm{m}$ nylon filters (Small Parts Inc. \#CMN-0105-A and CMN-0005-A) and centrifuged at $5,000 \times \mathrm{g}$ for 5 minutes at $4^{\circ} \mathrm{C}$. The pellet was resuspended in FSW, pelleted, and resuspended in $1 \mathrm{x}$ TAE buffer. 50 g molten $2 \%$ agarose (SeaKem ${ }^{\circ} \# 50152$ ) in $1 \mathrm{x}$ TAE was added to make plugs for genomic DNA extraction. The hardened plugs were treated with DNAse I $(0.25 \mathrm{U} / 50 \mu \mathrm{l})$ at $37^{\circ} \mathrm{C}$ for 10 minutes and then equilibrated in $\mathrm{TE}$ buffer for 30 minutes at room temperature. Agarose plugs were further processed using CHEF Mammalian Genomic DNA Plug Kit from Bio-Rad Laboratories (\#170-3591) according to the manufacturer's instructions. The protocol for pulse field gel electrophoresis (PFGE) and isolation of the bacterial chromosomes from the agarose plugs was adapted from Gil [112].

\section{Genome sequencing and assembly}

Genomic bacterial DNA was sequenced at the Institute for Genomic Research (TIGR), the Joint Genome Institute (JGI), and the University of California, Davis, using a diversity of sequencing technologies. Two Sanger libraries of $3-4 \mathrm{~Kb}$ and $10-12 \mathrm{~Kb}$ insert sizes were constructed as previously described [113]. Sequencing of these Sanger libraries resulted in 110,187 reads with N50 of 969 bp and the average coverage depth of $8 x$. Subsequently, using Roche 454 technology, 387,143 sequencing reads with the N50 of 207 bp and the average coverage depth of 13x were obtained. Then, 25,635,107 Illumina sequencing reads were generated. The Illumina sequences were 35 bp long and had the average coverage depth of 150x. These Sanger, Roche 454, and Illumina sequences were assembled using the Paracel Genome Assembler (Paracel Inc., Pasadena, CA) into 68 contigs. Next, symbiont DNA was sequenced using Pacific Biosciences (PacBio) technology, resulting in 150,000 reads with N50 of 4,966 bp and 9x coverage depth. The insertion and deletion (indels) errors, typical of the PacBio data [114], were reduced from $4 \%$ to $0.2 \%$ with Illumina paired-end sequences (500x coverage) 
using PacBioToCA program [115] available as a part of SMRT Analysis software package version 1.4 distributed by the Pacific Biosciences [116]. The error correction step also removed any PacBio sequences of the host origin, which, given the abundance of the symbionts in the gill tissue, had Illumina coverage below $5 x$. The Illumina data used for the error correction were generated as part of a different study and came from a specimen obtained at a different location (Point Judith, RI) than the rest of the genomic data. Due to the extent of the intra-species genomic sequence variation across geographic localities (Russell et al., in preparation), these Illumina data could not be used to supplement the genome assembly but were sufficient to correct the majority of sequencing indel errors in the PacBio reads. The error-corrected 54,684 PacBio sequences with N50 of 1,409 bp were used to connect the previous 68 genomic contigs into 30 larger scaffolds using the Automated Hybrid Assembly (AHA) module of SMRT Analysis. The resulting 7 gaps within the scaffolds, 2,272 bp in total, were then filled in with the PacBio error-corrected sequences using the PBJelly software tool [117], reducing the number of gaps to 4 and the total gap length to $100 \mathrm{bp}$. After discarding 20 of the smallest low coverage (2-9x) scaffolds that contained mostly eukaryotic genes ( $>65 \%)$, identified as described below, only 10 scaffolds were retained as a part of the symbiont genome.

\section{Sequence analysis}

Open reading frames (ORFs) on S. velum symbiont scaffolds were predicted using Glimmer [118], Prodigal [119], and GeneMarkS [120]. The software parameters used to perform these analyses are listed in Additional file 4: Table S4. Once identified, the ORFs were translated into protein-coding sequences and queried against the UniProt Reference Clusters (UniRef90) (20 November 2013) [121], National Center for Biotechnology Information non-redundant (NCBI-nr) (4 November 2013) [122], and M5 non-redundant (M5-nr) (27 January 2014) [123] databases for functional annotation using BLASTP (e-value cutoff 0.001) [38]. UniRef90 gene entries sharing the highest percent identity with the query and NCBI-nr and M5-nr entries with the highest bit score match to the query were retained for annotation. Genes predicted by two or more methods (redundant) were considered the same and collapsed into a single entry if they shared the same start and stop position, orientation, and similar functional annotations. Non-redundant entries (i.e., gene predictions unique to a given software) were also retained. Finally, the above predictions and annotations were reconciled with the genes predicted and annotated through the Integrated Microbial Genomes Expert Review (IMG-ER) pipeline [124]. Selected origins of replication were verified by Ori-Finder [125]. The genes in the genome was assigned taxa in the NCBI taxonomy based on the BLASTN [38] searches (-best_hit_overhang 0.25, -best_hit_score_edge 0.05 , -evalue 0.0001 ) against the NCBI-nr database (8 July 2014) computed with MEGAN 5.4.3 (maximum number of matches per read 100; LCA parameters: minimal support 5, minimal score 35, top percent 10) [39]. Selected promoters were identified with BPROM [126]. Signal peptides and transmembrane domains were predicted using SignalP 3.0 Server and TMHMM, respectively [127]. The Genomic Utility for Automated Comparison (GUAC) Python script (Additional file 5) was developed to inform comparative analyses of gene content across multiple genomes, in particular genes involved in sulfur-oxidation (Figure 4) and extracellular transport (Table 2). The GUAC software first identified those target genes in the genomes of interest that were annotated with unambiguous gene symbols (e.g. soxA). Next, using amino acid sequences of these genes as queries, BLASTP searched for homologous sequences in the remaining target genomes (default cut-off values: bit score 50, identity $30 \%$, alignment length over the source sequence $40 \%$ ). These sequences were aligned using ClustalW [128]. The alignments were used to manually verify the results (e.g., based on known conserved domains, etc.). Mobile genetic elements were detected by type. Insertion sequences were found using OASIS [129]. Integrative conjugative elements and plasmid as well as phage sequences were identified by BLASTN [38] searches against the ICEberg [130] and ACLAME [131] databases, respectively (cut-off values: 250 nucleotides alignment length and 90\% identity). To determine whether mobile genetic elements interrupted open reading frames, the nucleotide regions before and after each element were concatenated and aligned to the NCBI-nr sequences using BLASTN.

\section{Availability of supporting data}

This genome project has been deposited at DDBJ/EMBL/ GenBank under the accession JRAA00000000. The version described in this paper is version JRAA01000000.

\section{Additional files}

Additional file 1: Table S1. Length $[b p], G C \%$, percentage of the total
base pairs, and the number of genes in the scaffolds which constitute
the genome of the S. velum symbiont.
Additional file 2: Table S2. tRNA genes and the codon frequencies in
the genome of the S. velum symbiont.
Additional file 3: Table S3. Gene product names used in Figures 1 and
4, the corresponding NCBI protein ID reference numbers, and EC/TC
numbers.
Additional file 4: Table S4. Parameters of the gene prediction software.
Additional file 5: Genomic Utility for Automated Comparison (GUAC).
A Python script developed to inform comparative analyses of gene content
across multiple genomes.




\section{Competing interests}

The authors declare that they have no competing interests.

\section{Authors' contributions}

OD performed the DNA isolation and the final genome assembly, developed the Python GUAC script, carried out and coordinated the sequence analysis and the manual annotation, and drafted the manuscript. SLR, WTL, KMF, LL, and GR participated in the sequence analysis, the manual annotation, and the drafting of the manuscript. FJS carried out the DNA isolation, coordinated and participated in the gene prediction and the automated annotation. RS performed the gene prediction and the automated annotation. ILGN carried out the DNA isolation and participated in the sequence analysis. TW and JAE coordinated and participated in the genome sequencing, the initial genome assembly, and the preliminary gene prediction and annotation. DW and JML performed the initial genome assembly, gene prediction, and annotation. CMC and JAE conceived of the study, participated in its design and coordination, and helped draft the manuscript. All authors read and approved the final manuscript.

\section{Acknowledgments}

This work was funded by grant 0412205 of the US National Science Foundation (NSF) and was made possible with the generous support of the U.S. Department of Energy Joint Genome Institute (JGI). The work conducted by JGI was supported by the Office of Science of the U.S. Department of Energy under Contract No. DE-AC02-05CH11231. We would like to express special thanks to Grace Pai for creating Sanger sequencing libraries and Shannon Smith and Terry Utterback for coordinating sequencing at TIGR.

\section{Author details}

'Department of Organismic and Evolutionary Biology, Harvard University, 16 Divinity Avenue, 4081 Biological Laboratories, Cambridge, MA 02138, USA. ${ }^{2}$ Department of Civil and Environmental Engineering, Massachusetts Institute of Technology, 15 Vassar Street, Cambridge, MA 02139, USA. ${ }^{3}$ SOA Key Laboratory for Polar Science, Polar Research Institute of China, Shanghai 200136, China. ${ }^{4}$ Microbiology \& Systems Biology Group, TNO, Utrechtseweg 48, Zeist, Utrecht 3704HE, The Netherlands. ${ }^{5}$ School of Biology, Georgia Institute of Technology, Atlanta, GA 30332-0230, USA. ${ }^{6}$ Department of Biology, Indiana University, 1001 East 3rd Street, Jordan Hall, Bloomington, IN 47405, USA. 'DOE Joint Genome Institute, 2800 Mitchell Drive, Walnut Creek, CA 94598, USA. ${ }^{8}$ UC Davis Genome Center, 451 East Health Sciences Drive, Davis, CA 95616-8816, USA.

Received: 3 April 2014 Accepted: 23 September 2014

Published: 23 October 2014

\section{References}

1. Sagan L: On the origin of mitosing cells. J Theor Bio/ 1967, 14:225-274.

2. Gonzalez A, Clemente JC, Shade A, Metcalf JL, Song S, Prithiviraj B, Palmer BE, Knight R: Our microbial selves: what ecology can teach us. EMBO Rep 2011, 12:775-784.

3. Dilworth MJ, James EK, Sprent Jl: Nitrogen-Fixing Leguminous Symbioses. Kluwer Academic Pub; 2008.

4. Clark EL, Karley AJ, Hubbard SF: Insect endosymbionts: manipulators of insect herbivore trophic interactions? Protoplasma 2010, 244:25-51.

5. Cavanaugh CM, McKiness Z, Newton I, Stewart FJ: Marine chemosynthetic symbioses. In The Prokaryotes - Prokaryotic Biology and Symbiotic Associations. 3rd edition. Edited by Rosenberg E. 2013:579-607.

6. Toft C, Andersson SGE: Evolutionary microbial genomics: insights into bacterial host adaptation. Nat Rev Genet 2010, 11:465-475.

7. Woyke T, Tighe D, Mavromatis K, Clum A, Copeland A, Schackwitz W, Lapidus A, Wu D, McCutcheon JP, McDonald BR, Moran NA, Bristow J, Cheng J-F: One bacterial cell, one complete genome. PLoS One 2010, 5:1-8.

8. Kamke J, Sczyrba A, Ivanova N, Schwientek P, Rinke C, Mavromatis K, Woyke T, Hentschel U: Single-cell genomics reveals complex carbohydrate degradation patterns in poribacterial symbionts of marine sponges. ISME J 2013, 7:2287-2300.

9. Dubilier N, Bergin C, Lott C: Symbiotic diversity in marine animals: the art of harnessing chemosynthesis. Nat Rev Micro 2008, 6:725-740.

10. Cavanaugh CM: Symbiotic chemoautotrophic bacteria in marine invertebrates from sulphide-rich habitats. Nature 1983, 302:58-61.

11. Eisen JA, Smith SW, Cavanaugh CM: Phylogenetic relationships of chemoautotrophic bacterial symbionts of Solemya velum say
(Mollusca: Bivalvia) determined by $16 \mathrm{~S}$ rRNA gene sequence analysis. J Bacteriol 1992, 174:3416-3421.

12. Cavanaugh $\mathrm{CM}$, Abbott M, Veenhuis M: Immunochemical localization of ribulose-1, 5-bisphosphate carboxylase in the symbiont-containing gills of Solemya velum (Bivalvia: Mollusca). P Natl Acad Sci USA 1988, 85:7786-7789.

13. Scott KM, Cavanaugh $\mathrm{CM}: \mathrm{CO}_{2}$ uptake and fixation by endosymbiotic chemoautotrophs from the bivalve Solemya velum. Appl Environ Microb 2007, 73:1174-1179.

14. Conway N, Capuzzo J, Fry B: The role of endosymbiotic bacteria in the nutrition of Solemya velum: evidence from a stable isotope analysis of endosymbionts and host. Limnol Oceanogr 1989, 34:249-255.

15. Krueger DM, Gallager S, Cavanaugh CM: Suspension feeding on phytoplankton by Solemya velum, a symbiont-containing clam. Mar Ecol-Prog Ser 1992, 86:145-151.

16. Cary SC: Vertical transmission of a chemoautotrophic symbiont in the protobranch bivalve, Solemya reidi. Mol Mar Biol Biotechnol 1994, 3:121-130.

17. Krueger DM, Gustafson RG, Cavanaugh CM: Vertical transmission of chemoautotrophic symbionts in the bivalve Solemya velum (Bivalvia: Protobranchia). Biol Bull 1996, 190:195-202.

18. Peek A, Vrijenhoek R, Gaut B: Accelerated evolutionary rate in sulfur-oxidizing endosymbiotic bacteria associated with the mode of symbiont transmission. Mol Biol Evol 1998, 15:1514.

19. Hurtado LA, Mateos M, Lutz RA, Vrijenhoek RC: Coupling of bacterial endosymbiont and host mitochondrial genomes in the hydrothermal vent clam Calyptogena magnifica. Appl Environ Microb 2003, 69:2058-2064.

20. Kuwahara H, Yoshida T, Takaki Y, Shimamura S, Nishi S, Harada M, Matsuyama K, Takishita K, Kawato M, Uematsu K: Reduced genome of the thioautotrophic intracellular symbiont in a deep-sea clam, Calyptogena okutanii. Curr Biol 2007, 17:881-886.

21. Kuwahara H, Takaki Y, Yoshida T, Shimamura S, Takishita K, Reimer JD, Kato C, Maruyama T: Reductive genome evolution in chemoautotrophic intracellular symbionts of deep-sea Calyptogena clams. Extremophiles 2008, 12:365-374.

22. Newton I, Woyke T, Auchtung T, Dilly G, Dutton R, Fisher M, Fontanez K, Lau E, Stewart FJ, Richardson P: The Calyptogena magnifica chemoautotrophic symbiont genome. Science 2007, 315:998-1000.

23. Newton I, Girguis PR, Cavanaugh CM: Comparative genomics of vesicomyid clam (Bivalvia: Mollusca) chemosynthetic symbionts. BMC Genomics 2008, 9:585.

24. Peek A, Feldman R, Lutz R, Vrijenhoek R: Cospeciation of chemoautotrophic bacteria and deep sea clams. Proc Natl Acad Sci U S A 1998, 95:9962.

25. Stewart FJ, Young CR, Cavanaugh CM: Lateral symbiont acquisition in a maternally transmitted chemosynthetic clam endosymbiosis. Mol Biol Evol 2008, 25:673-687.

26. Stewart FJ, Young C, Cavanaugh CM: Evidence for homologous recombination in intracellular chemosynthetic clam symbionts. Mol Biol Evol 2009, 26:1391-1404.

27. Stewart FJ, Baik AHY, Cavanaugh CM: Genetic subdivision of chemosynthetic endosymbionts of Solemya velum along the Southern New England coast. Appl Environ Microb 2009, 75:6005-6007.

28. Krueger DM, Cavanaugh CM: Phylogenetic diversity of bacterial symbionts of Solemya hosts based on comparative sequence analysis of 16S rRNA genes. Appl Environ Microb 1997, 63:91.

29. Moran NA: Accelerated evolution and Muller's rachet in endosymbiotic bacteria. Proc Natl Acad Sci U S A 1996, 93:2873-2878.

30. Wu M, Sun LV, Vamathevan J, Riegler M, Deboy R, Brownlie JC, McGraw EA, Martin W, Esser C, Ahmadinejad N, Wiegand C, Madupu R, Beanan MJ, Brinkac LM, Daugherty SC, Durkin AS, Kolonay JF, Nelson WC, Mohamoud Y, Lee P, Berry K, Young MB, Utterback T, Weidman J, Nierman WC, Paulsen IT, Nelson KE, Tettelin H, O'Neill SL, Eisen JA: Phylogenomics of the reproductive parasite Wolbachia pipientis wMel: a streamlined genome overrun by mobile genetic elements. PLoS Biol 2004, 2:E69.

31. Robidart J, Bench S, Feldman R, Novoradovsky A, Podell S, Gaasterland T, Allen E, Felbeck H: Metabolic versatility of the Riftia pachyptila endosymbiont revealed through metagenomics. Environ Microbio/ 2008, 10:727-737.

32. Gardebrecht A, Markert S, Sievert SM, Felbeck $H$, Thürmer A, Albrecht D, Wollherr A, Kabisch J, Le Bris N, Lehmann R, Daniel R, Liesegang H, Hecker M, Schweder T: Physiological homogeneity among the endosymbionts of 
Riftia pachyptila and Tevnia jerichonana revealed by proteogenomics. ISME J 2012, 6:766-776.

33. Nakagawa S, Shimamura S, Takaki Y, Suzuki Y, Murakami S-I, Watanabe T, Fujiyoshi S, Mino S, Sawabe T, Maeda T, Makita H, Nemoto S, Nishimura S-I, Watanabe H, Watsuji T-O, Takai K: Allying with armored snails: the complete genome of gammaproteobacterial endosymbiont. ISME J 2014, 8:40-51

34. Woyke T, Teeling H, Ivanova NN, Huntemann M, Richter M, Gloeckner FO, Boffelli D, Anderson IJ, Barry KW, Shapiro HJ, Szeto E, Kyrpides NC, Mussmann M, Amann R, Bergin C, Ruehland C, Rubin EM, Dubilier N Symbiosis insights through metagenomic analysis of a microbial consortium. Nature 2006, 443:950-955.

35. Wu M, Eisen JA: A simple, fast, and accurate method of phylogenomic inference. Genome Biol 2008, 9:1-11.

36. Murphy FV, Ramakrishnan V: Structure of a purine-purine wobble base pair in the decoding center of the ribosome. Nat Struct Mol Biol 2004, 11:11251-11252.

37. Tatusov RL, Koonin EV, Lipman DJ: A genomic perspective on protein families. Science 1997, 278:631-637.

38. Altschul SF, Gish W, Miller W, Myers EW, Lipman DJ: Basic local alignment search tool. J Mol Biol 1990, 215:403-410.

39. Huson DH, Mitra S, Ruscheweyh H-J, Weber N, Schuster SC: Integrative analysis of environmental sequences using MEGAN4. Genome Res 2011, 21:1552-1560.

40. Stewart FJ, Dmytrenko O, DeLong E: Metatranscriptomic analysis of sulfur oxidation genes in the endosymbiont of Solemya velum. Frontiers Microbiol 2011, 2:1-10

41. Frigaard N-U, Dahl C: Sulfur metabolism in phototrophic sulfur bacteria. Adv Microb Physiol 2009, 54:103-200.

42. Walsh DA, Zaikova E, Howes CG, Song YC, Wright JJ, Tringe SG, Tortell PD, Hallam SJ: Metagenome of a versatile chemolithoautotroph from expanding oceanic dead zones. Science 2009, 326:578-582.

43. Dahl C, Prange A: Bacterial sulfur globules: occurrence, structure and metabolism. In Inclusions in Prokaryotes Microbiology Monographs, Volume 1. 2006:21-51.

44. Friedrich C, Bardischewsky F, Rother D, Quentmeier A, Fischer J: Prokaryotic sulfur oxidation. Curr Opin Microbiol 2005, 8:253-259.

45. Fisher C, Childress J, ARP A, BROOKS J, DISTEL D, Favuzzi J, Macko S, Newton A, Powell M, Somero G, SOTO T: Physiology, morphology, and biochemical composition of Riftia pachyptila at Rose Garden in 1985. Deep-Sea Res 1988, 35:1745-1758.

46. Vetter RD: Elemental sulfur in the gills of three species of clams containing chemoautotrophic symbiotic bacteria: a possible inorganic energy storage compound. Mar Biol 1985, 88:33-42.

47. Childress JJ, Girguis PR: The metabolic demands of endosymbiotic chemoautotrophic metabolism on host physiological capacities. J Exp Biol 2011, 214:312-325.

48. Cort JR, Selan U, Schulte A, Grimm F, Kennedy MA, Dahl C: Allochromatium vinosum DsrC: Solution-state NMR structure, redox properties, and interaction with DsrEFH, a protein essential for purple sulfur bacterial sulfur oxidation. J Mol Biol 2008, 382:692-707.

49. Oliveira TF, Vonrhein C, Matias PM, Venceslau SS, Pereira IAC, Archer M: Purification, crystallization and preliminary crystallographic analysis of a dissimilatory DsrAB sulfite reductase in complex with DsrC. J Struct Biol 2008, 164:236-239.

50. Ghosh W, Dam B: Biochemistry and molecular biology of lithotrophic sulfur oxidation by taxonomically and ecologically diverse bacteria and archaea. Fems Microbiol Rev 2009, 33:999-1043.

51. Chen C, Rabourdin B, Hammen C: The effect of hydrogen sulfide on the metabolism of Solemya velum and enzymes of sulfide oxidation in gill tissue. Comp Biochem Physiol B Biochem Mol Biol 1987, 88:949-952.

52. Biegel E, Schmidt S, González JM, Müller V: Biochemistry, evolution and physiological function of the Rnf complex, a novel ion-motive electron transport complex in prokaryotes. Cell Mol Life Sci 2011, 68:613-634.

53. Bruschi M, Guerlesquin F: Structure, function and evolution of bacterial ferredoxins. Fems Microbiol Rev 1988, 4:155-175.

54. Kovács KL, Kovács AT, Maróti G, Mészáros LS, Balogh J, Latinovics D, Fülöp A, Dávid R, Dorogházi E, Rákhely G: The hydrogenases of Thiocapsa roseopersicina. Biochem Soc Trans 2005, 33:61-63.

55. Burgdorf T, Lenz O, Buhrke T, van der Linden E, Jones A, Albracht S, Friedrich B: [NiFe]-hydrogenases of Ralstonia eutropha H16: Modular enzymes for oxygen-tolerant biological hydrogen oxidation. $J \mathrm{Mol}$ Microb Biotech 2005, 10:181-196.

56. Vignais PM, Billoud B: Occurrence, classification, and biological function of hydrogenases: an overview. Chem Rev 2007, 107:4206-4272.

57. Maroti J, Farkas A, Nagy IK, Maroti G, Kondorosi E, Rakhely G, Kovacs KL: A second soluble hox-type nife enzyme completes the hydrogenase set in Thiocapsa roseopersicina BBS. Appl Environ Microbiol 2010, 76:5113-5123.

58. Petersen JM, Zielinski FU, Pape T, Seifert R, Moraru C, Amann R, Hourdez S, Girguis PR, Wankel SD, Barbe V, Pelletier E, Fink D, Borowski C, Bach W, Dubilier $\mathrm{N}$ : Hydrogen is an energy source for hydrothermal vent symbioses. Nature 2011, 476:176-180.

59. Bogachev AV, Verkhovsky MI: $\mathrm{Na}^{+}$-translocating NADH: quinone oxidoreductase: progress achieved and prospects of investigations. Biochem (Moscow) 2005, 70:143-149.

60. Shigenobu S, Watanabe H, Hattori M, Sakaki Y, Ishikawa H: Genome sequence of the endocellular bacterial symbiont of aphids Buchnera sp. APS. Nature 2000, 407:81-86.

61. Pickering BS, Oresnik IJ: Formate-dependent autotrophic growth in Sinorhizobium meliloti. J Bacteriol 2008, 190:6409.

62. Benoit S, Abaibou H, Mandrand-Berthelot M-A: Topological analysis of the aerobic membrane-bound formate dehydrogenase of Escherichia coli. J Bacteriol 1998, 180:6625.

63. Preisig O, Zufferey R, Thony-Meyer L, Appleby C, Hennecke H: $\mathrm{A}$ high-affinity $\mathrm{Cb}_{3}$-type cytochrome oxidase terminates the symbiosis- specific respiratory chain of Bradyrhizobium japonicum. J Bacteriol 1996, 178:1532.

64. Pitcher RS, Watmough NJ: The bacterial cytochrome $c b b_{3}$ oxidases. Biochim Biophys Acta Bioenerg 2004, 1655:388-399.

65. Nunoura T, Sako Y, Wakagi T, Uchida A: Regulation of the aerobic respiratory chain in the facultatively aerobic and hyperthermophilic archaeon Pyrobaculum oguniense. Microbiol (Reading, Engl) 2003, 149:673-688.

66. Otten MF, Stork DM, Reijnders WN, Westerhoff HV, Van Spanning RJ: Regulation of expression of terminal oxidases in Paracoccus denitrificans. Eur J Biochem 2001, 268:2486-2497.

67. Krueger DM, Roeselers G, Sigman D, Cavanaugh CM: Nitrogen nutrition in the symbiosis Solemya velum. in preparation.

68. Potter LC, Millington P, Griffiths L, Thomas GH, Cole JA: Competition between Escherichia coli strains expressing either a periplasmic or a membrane-bound nitrate reductase: does Nap confer a selective advantage during nitrate-limited growth? Biochem J 1999, 344(Pt 1):77-84.

69. Zemmelink H, Houghton L, Sievert S, Frew N, Dacey J: Gradients in dimethylsuffide, dimethylsulfoniopropionate, dimethylsulfoxide, and bacteria near the sea surface. Mar Ecol-Prog Ser 2005, 295:33-42.

70. Mussmann M, Hu FZ, Richter M, de Beer D, Preisler A, Jorgensen BB, Huntemann M, Gloeckner FO, Amann R, Koopman WJH, Lasken RS, Janto B, Hogg J, Stoodley P, Boissy R, Ehrlich GD: Insights into the genome of large sulfur bacteria revealed by analysis of single filaments. PLOS Biol 2007, 5:1923-1937.

71. McCrindle SL, Kappler U, McEwan AG: Microbial dimethylsulfoxide and trimethylamine-N-oxide respiration. Adv Microb Physiol 2005, 50:147-198.

72. Häse CC, Fedorova ND, Galperin MY, Dibrov PA: Sodium ion cycle in bacterial pathogens: evidence from cross-genome comparisons. Microbiol Mol Biol Rev 2001, 65:353-370. table of contents.

73. Mulkidjanian AY, Dibrov P, Galperin MY: The past and present of sodium energetics: may the sodium-motive force be with you. Biochim Biophys Acta 2008, 1777:985-992

74. Robinson J, Cavanaugh CM: Expression of form I and form II Rubisco in chemoautotrophic symbioses: implications for the interpretation of stable carbon isotope values. Limnol Oceanogr 1995, 40:1496-1502.

75. Reshetnikov AS, Rozova ON, Khmelenina VN, Mustakhimov II, Beschastny AP, Murrell JC, Trotsenko YA: Characterization of the pyrophosphatedependent 6-phosphofructokinase from Methylococcus capsulatus Bath. FEMS Microbiol Lett 2008, 288:202-210.

76. Markert S, Gardebrecht A, Felbeck H, Sievert SM, Klose J, Becher D, Albrecht D, Thürmer A, Daniel R, Kleiner M, Hecker M, Schweder T: Status quo in physiological proteomics of the uncultured Riftia pachyptila endosymbiont. Proteomics 2011, 11:3106-3117.

77. Kleiner M, Wentrup C, Lott C, Teeling H, Wetzel S, Young J, Chang Y-J, Shah M, VerBerkmoes NC, Zarzycki J, Fuchs G, Markert S, Hempel K, Voigt B, Becher D, Liebeke M, Lalk M, Albrecht D, Hecker M, Schweder T, Dubilier N: 
Metaproteomics of a gutless marine worm and its symbiotic microbial community reveal unusual pathways for carbon and energy use. Proc Natl Acad Sci 2012, 109:E1173-E1182.

78. Bassham J, Benson A, Calvin M: The path of carbon in photosynthesis. J Biol Chem 1950, 185:781-787.

79. Fenton A, Paricharttanakul N, Reinhart G: Identification of substrate contact residues important for the allosteric regulation of phosphofructokinase from Eschericia coli. Biochemistry 2003, 42:6453-6459.

80. Purves J, Cockayne A, Moody PCE, Morrissey JA: Comparison of the regulation, metabolic functions, and roles in virulence of the glyceraldehyde-3-phosphate dehydrogenase homologues gapA and gapB in Staphylococcus aureus. Infect Immun 2010, 78:5223-5232.

81. Wood AP, Aurikko JP, Kelly DP: A challenge for 21 st century molecular biology and biochemistry: what are the causes of obligate autotrophy and methanotrophy? Fems Microbiol Rev 2004, 28:335-352

82. Han SO, Inui M, Yukawa H: Effect of carbon source availability and growth phase on expression of Corynebacterium glutamicum genes involved in the tricarboxylic acid cycle and glyoxylate bypass. Microbiology 2008, 154:3073-3083.

83. Lee $\mathrm{R}$, Thuesen $\mathrm{E}$, Childress J: Ammonium and free amino acids as nitrogen sources for the chemoautotrophic symbiosis Solemya reidi Bernard (Bivalvia: Protobranchia). J Exp Mar Biol Ecol 1992, 158:75-91.

84. Liao L, Wankel SD, Wu M, Cavanaugh CM, Girguis PR: Characterizing the plasticity of nitrogen metabolism by the host and symbionts of the hydrothermal vent chemoautotrophic symbioses Ridgeia piscesae. Mol Ecol 2013.

85. Lee RW, Childress JJ: Assimilation of inorganic nitrogen by marine invertebrates and their chemoautotrophic and methanotrophic symbionts. App/ Environ Microb 1994, 60:1852-1858.

86. Bourbonnais A, Lehmann MF, Butterfield DA, Juniper SK: Subseafloor nitrogen transformations in diffuse hydrothermal vent fluids of the Juan de Fuca Ridge evidenced by the isotopic composition of nitrate and ammonium. Geochem Geophys Geosyst 2012, 13:1-23.

87. Hentschel $U$, Felbeck $H$ : Nitrate respiration in the hydrothermal vent tubeworm Riftia pachyptila. Nature 1993, 366:338-340

88. Lee R, Robinson J, Cavanaugh CM: Pathways of inorganic nitrogen assimilation in chemoautotrophic bacteria-marine invertebrate symbioses: expression of host and symbiont glutamine synthetase. J Exp Biol 1999, 202(Pt 3):289-300.

89. Girguis PR, Lee RW, Desaulniers N, Childress JJ, Pospesel M, Felbeck H, Zal F: Fate of nitrate acquired by the tubeworm Riftia pachyptila. Appl Environ Microbiol 2000, 66:2783-2790.

90. Beckers G, Bendt AK, Kramer R, Burkovski A: Molecular identification of the urea uptake system and transcriptional analysis of urea transporter and urease-encoding genes in Corynebacterium glutamicum. J Bacterio/ 2004, 186:7645.

91. De Cian M, Regnault M, Lallier FH: Nitrogen metabolites and related enzymatic activities in the body fluids and tissues of the hydrothermal vent tubeworm Riftia pachyptila. J Exp Biol 2000, 203:2907-2920.

92. Joyner $\mathrm{L}$, Peyer SM, Lee RW: Possible roles of sulfur-containing amino acids in a chemoautotrophic bacterium-mollusc symbiosis. Biol Bull 2003, 205:331-338.

93. Conway N, Howes B, McDowell Capuzzo J, Turner R, Cavanaugh CM: Characterization and site description of Solemya borealis (Bivalvia; Solemyidae), another bivalve-bacteria symbiosis. Mar Biol 1992 112:601-613.

94. Eichhorn E, van der Ploeg JR, Kertesz MA, Leisinger T: Characterization of alpha-ketoglutarate-dependent taurine dioxygenase from Escherichia coli. J Biol Chem 1997, 272:23031-23036.

95. Conway N, McDowell Capuzzo J: Incorporation and utilization of bacterial lipids in the Solemya velum symbiosis. Mar Biol 1991, 108:277-291.

96. Karow M, Georgopoulos C: Isolation and characterization of the Escherichia coli msbB gene, a multicopy suppressor of null mutations in the high-temperature requirement gene htrB. J Bacteriol 1992, 174:702-710

97. Moran N, McCutcheon J, Nakabachi A: Genomics and evolution of heritable bacterial symbionts. Annu Rev Genet 2008, 42:165-190.

98. Nussbaumer AD, Fisher CR, Bright M: Horizontal endosymbiont transmission in hydrothermal vent tubeworms. Nature 2006, 441:345-348.
99. Cavanaugh CM: Symbiosis of chemoautotrophic bacteria and marine invertebrates. In PhD Thesis. Cambridge, MA, USA: Harvard University, Department of Organismic and Evolutionary Biology; 1985.

100. Fisher C, Childress J: Organic carbon transfer from methanotrophic symbionts to the host hydrocarbon-seep mussel. Symbiosis 1992, 12:221-235.

101. Saurin W, Hofnung M, Dassa E: Getting in or out: early segregation between importers and exporters in the evolution of ATP-binding cassette (ABC) transporters. J Mol Evol 1999, 48:22-41.

102. van de Velde W, Zehirov G, Szatmari A, Debreczeny M, Ishihara H, Kevei Z, Farkas A, Mikulass K, Nagy A, Tiricz H: Plant peptides govern terminal differentiation of bacteria in symbiosis. Science 2010, 327:1122-1125.

103. Paau AS, Bloch CB, Brill WJ: Developmental fate of Rhizobium meliloti bacteroids in alfalfa nodules. J Bacteriol 1980, 143:1480-1490.

104. Stewart FJ, Cavanaugh CM: Bacterial endosymbioses in Solemya (Mollusca: Bivalvia) - model systems for studies of symbiont-host adaptation. Antonie Van Leeuwenhoek 2006, 90:343-360.

105. Whitchurch CB, Leech AJ, Young MD, Kennedy D, Sargent JL, Bertrand J J, Semmler ABT, Mellick AS, Martin PR, Alm RA, Hobbs M, Beatson SA, Huang B, Nguyen L, Commolli JC, Engel JN, Darzins A, Mattick JS: Characterization of a complex chemosensory signal transduction system which controls twitching motility in Pseudomonas aeruginosa. Mol Microbiol 2004, 52:873-893.

106. Newton ILG, Bordenstein SR: Correlations between bacterial ecology and mobile DNA. Curr Microbiol 2011, 62:198-208.

107. Plague GR, Dunbar HE, Tran PL, Moran NA: Extensive proliferation of transposable elements in heritable bacterial symbionts. J Bacteriol 2008, 190:777-779.

108. Gil R, Latorre A, Moya A: Evolution of prokaryote-animal symbiosis from a genomics perspective. In Microbiology Monographs, Volume 19. Berlin, Heidelberg: Springer Berlin Heidelberg; 2010:207-233.

109. Cordaux R, Pichon S, Ling A, Pérez P, Delaunay C, Vavre F, Bouchon D, Grève P: Intense transpositional activity of insertion sequences in an ancient obligate endosymbiont. Mol Biol Evol 2008, 25:1889-1896.

110. Chafee ME, Funk DJ, Harrison RG, Bordenstein SR: Lateral phage transfer in obligate intracellular bacteria (wolbachia): verification from natural populations. Mol Biol Evol 2010, 27:501-505.

111. Roeselers G, Newton ILG: On the evolutionary ecology of symbioses between chemosynthetic bacteria and bivalves. Appl Microbiol Biotechnol 2012, 94:1-10

112. Gil R, Sabater-Muñoz B, Latorre A, Silva FJ, Moya A: Extreme genome reduction in Buchnera spp.: toward the minimal genome needed for symbiotic life. Proc Natl Acad Sci U S A 2002, 99:4454-4458.

113. Wu D, Daugherty SC, Van Aken SE, Pai GH, Watkins KL, Khouri H, Tallon LJ, Zaborsky JM, Dunbar HE, Tran PL, Moran NA, Eisen JA: Metabolic complementarity and genomics of the dual bacterial symbiosis of sharpshooters. PLoS Biol 2006, 4:1079-1092.

114. Eid J, Fehr A, Gray J, Luong K, Lyle J, Otto G, Peluso P, Rank D, Baybayan P, Bettman B, Bibillo A, Bjornson K, Chaudhuri B, Christians F, Cicero R, Clark S, Dalal R, Dewinter A, Dixon J, Foquet M, Gaertner A, Hardenbol P, Heiner C, Hester K, Holden D, Kearns G, Kong X, Kuse R, Lacroix Y, Lin S, et al: Real-time DNA sequencing from single polymerase molecules. Science 2009, 323:133-138.

115. Koren S, Schatz MC, Walenz BP, Martin J, Howard JT, Ganapathy G, Wang Z, Rasko DA, McCombie WR, Jarvis ED, Phillippy AM: Hybrid error correction and de novo assembly of single-molecule sequencing reads. Nat Biotechnol 2012

116. Pacific Biosciences. [http://www.pacb.com]

117. English AC, Richards S, Han Y, Wang M, Vee V, Qu J, Qin X, Muzny DM, Reid JG, Worley KC, Gibbs RA: Mind the Gap: Upgrading Genomes with Pacific Biosciences RS Long-Read Sequencing Technology. PLOS ONE 2012, 7:e47768.

118. Delcher AL, Bratke KA, Powers EC, Salzberg SL: Identifying bacterial genes and endosymbiont DNA with Glimmer. Bioinformatics 2007, 23:673-679.

119. Hyatt D, Chen G-L, LoCascio PF, Land ML, Larimer FW, Hauser LJ: Prodigal: prokaryotic gene recognition and translation initiation site identification. BMC Bioinformatics 2010, 11:1-11.

120. Besemer J, Lomsadze A, Borodovsky M: GeneMarkS: a self-training method for prediction of gene starts in microbial genomes. Implications for finding sequence motifs in regulatory regions. Nucleic Acids Res 2001, 29:2607. 
121. Suzek BE, Huang H, McGarvey P, Mazumder R, Wu CH: UniRef: comprehensive and non-redundant UniProt reference clusters. Bioinformatics 2007, 23:1282-1288.

122. Tatusova T, Ciufo S, Fedorov B, O'Neill K, Tolstoy I: RefSeq microbial genomes database: new representation and annotation strategy. Nucleic Acids Res 2014, 42:D553-D559.

123. Wilke A, Harrison T, Wilkening J, Field D, Glass EM, Kyrpides N, Mavrommatis $\mathrm{K}$, Meyer F: The M5nr: a novel non-redundant database containing protein sequences and annotations from multiple sources and associated tools. BMC Bioinformatics 2012, 13:1-5.

124. Standard operating procedure for the annotations of genomes and metagenomes submitted to the integrated microbial genomes expert review (IMG-ER) system. [http://img.jgi.doe.gov/w/doc/img_er_ann.pdf]

125. Gao F, Zhang C-T: Ori-Finder: A web-based system for finding oriCs in unannotated bacterial genomes. BMC Bioinformatics 2009, 9:1-6

126. Bprom. [http://www.softberry.com]

127. Emanuelsson O, Brunak S, von Heijne G, Nielsen H: Locating proteins in the cell using TargetP, SignalP and related tools. Nat Protoc 2007, 2:953-971.

128. Larkin MA, Blackshields G, Brown NP, Chenna R, McGettigan PA, McWilliam H, Valentin F, Wallace IM, Wilm A, Lopez R, Thompson JD, Gibson TJ, Higgins DG: Clustal W and Clustal X version 2.0. Bioinformatics 2007, 23:2947-2948.

129. Robinson DG, Lee M-C, Marx CJ: OASIS: an automated program for global investigation of bacterial and archaeal insertion sequences. Nucleic Acids Res 2012, 40:e174

130. Bi D, Xu Z, Harrison EM, Tai C, Wei Y, He X, Jia S, Deng Z, Rajakumar K Ou H-Y: ICEberg: a web-based resource for integrative and conjugative elements found in Bacteria. Nucleic Acids Res 2012, 40(Database issue):D621-D626.

131. Leplae R, Lima-Mendez G, Toussaint A: ACLAME: a CLAssification of Mobile genetic Elements, update 2010. Nucleic Acids Res 2010 38(Database issue):D57-D61.

doi:10.1186/1471-2164-15-924

Cite this article as: Dmytrenko et al: The genome of the intracellular bacterium of the coastal bivalve, Solemya velum: a blueprint for thriving in and out of symbiosis. BMC Genomics 2014 15:924.

\section{Submit your next manuscript to BioMed Central and take full advantage of:}

- Convenient online submission

- Thorough peer review

- No space constraints or color figure charges

- Immediate publication on acceptance

- Inclusion in PubMed, CAS, Scopus and Google Scholar

- Research which is freely available for redistribution 